\title{
Collagen XIII Is Required for Neuromuscular Synapse Regeneration and Functional Recovery after Peripheral Nerve Injury
}

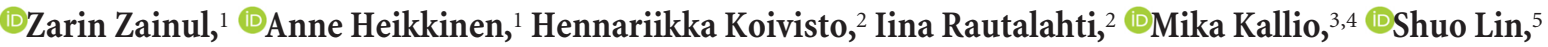

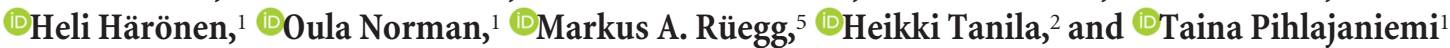 \\ ${ }^{1}$ Center for Cell-Matrix Research, Biocenter Oulu, Faculty of Biochemistry and Molecular Medicine, University of Oulu, 90014 Oulu, Finland, ${ }^{2}$ A.I. Virtanen \\ Institute, University of Eastern Finland, 70211 Kuopio, Finland, ${ }^{3}$ Department of Clinical Neurophysiology, Oulu University Hospital, 90220 Oulu, Finland, \\ ${ }^{4}$ Medical Imaging Physics and Technology-Research Group, University of Oulu, 90220 Oulu, Finland, and 5Biozentrum, University of Basel, CH-4056 Basel, \\ Switzerland
}

Collagen XIII occurs as both a transmembrane-bound and a shed extracellular protein and is able to regulate the formation and function of neuromuscular synapses. Its absence results in myasthenia: presynaptic and postsynaptic defects at the neuromuscular junction (NMJ), leading to destabilization of the motor nerves, muscle regeneration and atrophy. Mutations in COL13A1 have recently been found to cause congenital myasthenic syndrome, characterized by fatigue and chronic muscle weakness, which may be lethal. We show here that muscle defects in collagen XIII-deficient mice stabilize in adulthood, so that the disease is not progressive until very late. Sciatic nerve crush was performed to examine how the lack of collagen XIII or forced expression of its transmembrane form affects the neuromuscular synapse regeneration and functional recovery following injury. We show that collagen XIII-deficient male mice are unable to achieve complete NMJ regeneration and functional recovery. This is mainly attributable to presynaptic defects that already existed in the absence of collagen XIII before injury. Shedding of the ectodomain is not required, as the transmembrane form of collagen XIII alone fully rescues the phenotype. Thus, collagen XIII could serve as a therapeutic agent in cases of injury-induced PNS regeneration and functional recovery. We conclude that intrinsic alterations at the NMJ in Col13a1 ${ }^{-1-}$ mice contribute to impaired and incomplete NMJ regeneration and functional recovery after peripheral nerve injury. However, such alterations do not progress once they have stabilized in early adulthood, emphasizing the role of collagen XIII in NMJ maturation.

Key words: aging; collagen XIII; neuromuscular junction; peripheral nerve injury; recovery; regeneration

Significance Statement

Collagen XIII is required for gaining and maintaining the normal size, complexity, and functional capacity of neuromuscular synapses. Loss-of-function mutations in COL13A1 cause congenital myasthenic syndrome 19, characterized by postnatally progressive muscle fatigue, which compromises patients' functional capacity. We show here in collagen XIII-deficient mice that the disease stabilizes in adulthood once the NMJs have matured. This study also describes a relevant contribution of the altered NMJ morphology and function to neuromuscular synapses, and PNS regeneration and functional recovery in collagen XIII-deficient mice after peripheral nerve injury. Correlating the animal model data on collagen XIII-associated congenital myasthenic syndrome, it can be speculated that neuromuscular connections in congenital myasthenic syndrome patients are not able to fully regenerate and restore normal functionality if exposed to peripheral nerve injury.

\section{Introduction}

A neuromuscular junction (NMJ) is a chemical synapse between a branch of a motor neuron and a muscle fiber. During embryonic development, motor axons grow out from the spinal cord to innervate distal muscle targets (Punga and Rüegg, 2012; Darabid et al., 2014). Rare neuromuscular disorders, such as spi- 
nal muscular atrophy, amyotrophic lateral sclerosis, Charcot Marie Tooth syndrome, myasthenia gravis, Lambert-Eaton myasthenic syndrome, and congenital myasthenic syndrome (CMS), affect different aspects of the nerve-muscle connection (Hettwer et al., 2014; Barik et al., 2016; Souza et al., 2016). Logan and colleagues have recently described a new autosomal recessive, very early-onset CMS resulting from homozygous mutations in the COL13A1 gene, coding for the $\alpha 1$ chain of type XIII collagen, a membrane-associated collagen with interrupted triple-helices (MACIT) reportedly involved in NMJ maturation in mice (Latvanlehto et al., 2010; Logan et al., 2015; Tu et al., 2015).

Murine studies have shown that muscle-derived collagen XIII contributes to both presynaptic and postsynaptic maturation, as mice lacking collagen XIII have fewer active zones, aberrant AChR clustering, and impaired presynaptic and postsynaptic alignment (Latvanlehto et al., 2010; Härönen et al., 2017). The ectodomain of the transmembrane collagen XIII can be shed into the synaptic cleft; thus, it could be regarded as both a synaptic basement membrane component and a postsynaptic adhesion molecule/receptor (Hägg et al., 1998; Väisänen et al., 2004; Latvanlehto et al., 2010). Collagen XIII is known to stabilize postsynaptic, synaptic, and presynaptic integrity and to be required for gaining and maintaining the normal size, complexity, and functional capacity of neuromuscular synapses (Latvanlehto et al., 2010; Härönen et al., 2017). Collagen XIII participates in transsynaptic adhesion, contributing to axon recognition during development (data not shown), and to nerve terminal stabilization and differentiation in the postnatal maturation and maintenance of the NMJ (Latvanlehto et al., 2010; Härönen et al., 2017).

NMJs in adult animals are remarkably stable in their structure (Darabid et al., 2014), but they do change dramatically in circumstances, such as development (Balice-Gordon and Lichtman, 1993; Marques et al., 2000), aging (Valdez et al., 2010; Li et al., 2011), disease (Blake et al., 2002; Schaefer et al., 2005; Serra et al., 2012), and reinnervation following nerve injury (Rich and Lichtman, 1989; Kang et al., 2014). Axons that are injured and thus disconnected from their muscle fibers have a remarkable ability to regenerate (Fawcett and Keynes, 1990; Kang et al., 2003; Kang et al., 2014), but peripheral nerve regeneration and functional recovery can often remain incomplete, leaving permanent physical defects that compromise quality of life (Sulaiman and Gordon, 2013).

Peripheral nerve regeneration is a multistep process that is followed, for example, by chromatolysis, Wallerian degeneration, Schwann cell proliferation, and axon sprouting and elongation. Extracellular matrix molecules are known to support axonal extension and act as cues for nerve regeneration. For example, fibronectin, collagen, and laminin, when incorporated into a conduit, can act as cues for the regenerating axon (Griffin et al., 2014), whereas collagen XIII has been shown to ensure the presynaptic and postsynaptic integrity of NMJs (Latvanlehto et al., 2010; Härönen et al., 2017). Loss-of-function analysis has not been used, however, to investigate the role of collagen XIII in axon, muscle, and NMJ regeneration and functional recovery following peripheral nerve injury. We report here on sciatic nerve crush experiments performed using wild-type, collagen

Correspondence should be addressed to Dr. Pihlajaniemi Taina, Center for Cell-Matrix Research, Biocenter Oulu, Faculty of Biochemistry and Molecular Medicine, P0 Box 5400, University of Oulu, 90014 Oulu, Finland. E-mail: taina.pihlajaniemi@oulu.fi.

DOI:10.1523/JNEUROSCI.3119-17.2018

Copyright $\odot 2018$ the authors $\quad 0270-6474 / 18 / 384244-16 \$ 15.00 / 0$
XIII knock-out $\left(\right.$ Coll $\left._{3 a 1^{-/-}}\right)$and collagen XIII mutant mice $\left(\right.$ Col13a $1^{\mathrm{tm} / \mathrm{tm}}$ mice possessing only the transmembrane form of collagen XIII, eliminating shedding) to address the question of whether collagen XIII and its two distinct forms contribute to peripheral nerve injury-induced NMJ regeneration and functional recovery and, if so, how. We also sought to clarify the role of collagen XIII in physiological aging. As shown here, collagen XIII deficiency-induced muscle defects in mutant mice stabilize in adulthood and do not progress until at least 90 weeks of age. Importantly, our data show that collagen XIII is essential for complete NMJ regeneration and functional recovery after peripheral nerve injury.

\section{Materials and Methods}

Experimental animals. C57BL/6J-backcrossed collagen XIII knock-out mice (Col13a1 ${ }^{-1-}$; catalog \#4838425, RRID:MGI:4838425) (Latvanlehto et al., 2010) and transmembrane collagen XIII mice (Col13a1 ${ }^{\mathrm{tm} / \mathrm{tm}}$; IMSR catalog \#EM:09323, RRID:IMSR_EM:09323) (Härönen et al., 2017), and offspring of the former crossbred with B6.Cg-Tg(Thy-1/ YFP) 16Jrs/J mice (IMSR catalog \#JAX:003709, RRID:IMSR_JAX: 003709) (Feng et al., 2000), provided by The Jackson Laboratory, were used in the experiments. Male mice carrying the YFP marker in their neurons were used for the nerve crush experiment at 9-10 weeks of age and for the subsequent analyses of NMJs, muscles, and nerves. Female mice carrying the YFP marker in their neurons were used for the analyses of NMJs, muscles, and nerves at the age of 64 weeks, and similar analyses were performed with female mice without a marker at the age of 90 weeks. Both female and male mice without a marker transgene were used for behavioral tests at 52 weeks of age, and 68-week-old female mice were used for nerve conduction studies. Wild-type littermates were used as controls. The mice were maintained in the University of Oulu Animal Facility, where the nerve crush experimentation combined with functional analyses and nerve conduction studies were also performed, whereas the behavioral tests on aged animals were performed at the University of Eastern Finland. Permission to perform the experiments was obtained from the Finnish Animal Care and Use Committee. All the mouse experiments were conducted according to the European Community Council Directive (September 22, 2010; 2010/63/EEC), national legislation, and existing regulations for the care and use of laboratory animals.

Sciatic nerve injury procedure. The 9- to 10-week-old male mice were given pain relief, buprenorphine $(0.1 \mathrm{mg} / \mathrm{kg})$, subcutaneously $30 \mathrm{~min}$ before sciatic nerve injury performed under isoflurane inhalant anesthesia. An incision was made in the skin and mid-thigh muscle of the hind left limb under a microscope to expose the sciatic nerve, which was then carefully lifted with a glass loop, crushed for $20 \mathrm{~s}$ using No. 5 Jeweler's forceps, and then returned to its position. The skin incision was closed with a 5-0 absorbable Vicryl suture (Johnson\&Johnson). The right contralateral limb and nerve served as controls. Pain medication was continued for $3 \mathrm{~d}$ at $12 \mathrm{~h}$ intervals. The mice were tested for sciatic nerve function and muscle strength before injury and at 1, 1.5, 2, 3, 4, and 6 weeks after injury and euthanized for sample collection at 2, 3, 4, or 6 weeks after injury.

Whole-mount immunofluorescent staining. For immunostainings of the postinjury soleus and contralateral control muscles, and diaphragm and sciatic nerve, samples were dissected out and fixed in 2\% PFA/PBS at room temperature for $10 \mathrm{~min}$, after which they were rinsed 3 times with PBS at room temperature for $10 \mathrm{~min}$. The soleus muscles were cut into as thin bundles as possible and permeabilized with $1 \%$ Triton X-100/PBS for $2 \mathrm{~h}$ at $4^{\circ} \mathrm{C}$. They were then neutralized with $100 \mathrm{~mm}$ glycine/PBS at room temperature for 15 min to block excessive PFA. The samples were blocked with blocking buffer (2.5\% BSA, 2.5\% FCS, $0.2 \%$ Triton X-100 in PBS) at $4^{\circ} \mathrm{C}$ for $30 \mathrm{~min}$ and incubated with rabbit anti-mouse collagen XIII primary antibody (Kvist et al., 2001) or with rat antimouse CD31 (1:100, BD Biosciences catalog \#550274, RRID:AB_393571) together with mouse antihuman neurofilament (1:200, Neomarkers; Lab Vision catalog \#MS-359-S1, RRID:AB_61368), diluted with blocking buffer, at $4^{\circ} \mathrm{C}$ overnight followed by PBS washes 3 times at $4^{\circ} \mathrm{C}$ for at least 
$4 \mathrm{~h}$ together. The samples were incubated with a 405 AlexaFluor-conjugated goat anti-mouse (1:100, Invitrogen catalog \#A-31553, RRID: AB_221604), Cy2-conjugated goat anti-rat (1:300, Jackson ImmunoResearch Laboratories catalog \#112-225-167, RRID:AB_2338278), and/or Cy3-conjugated goat anti-rabbit secondary antibody ( $1: 300$, Jackson ImmunoResearch Laboratories catalog \#111-165-144, RRID:AB_2338006), and/or CF 405S/488 AlexaFluor-conjugated $\alpha$-bungarotoxin ( $\alpha$-BTX, 1:1000, Biotium, Invitrogen), diluted with blocking buffer for $4 \mathrm{~h}$ at $4^{\circ} \mathrm{C}$ followed by washing as described above. They were then imbedded in aqueous-based mounting medium (IMMU-MOUNT, Shandon) and imaged with a Zeiss Cell Observer spinning disc confocal microscope using a $100 \times$ objective or Olympus FluoView 1000 with $20 \times$ and $10 \times$ objectives.

For morphological evaluation of NMJ regeneration, postinjury soleus and extensor digitorum longus (EDL) and contralateral control muscles, and muscles from aged mice were dissected out and weighed. The muscles were then pinned onto a Sylgard-coated Petri dish and 594 AlexaFluor-conjugated $\alpha$-BTX in PBS was injected intramuscularly, followed by a $30 \mathrm{~min}$ incubation at room temperature, 3 short washes with PBS at room temperature and fixation with $4 \%$ PFA at room temperature for $10 \mathrm{~min}$, and then followed by PBS washes as before. The muscle ends were cut out and the muscles opened up without damaging the nerves innervating the muscle tissue. Tiled images of the mounted samples were captured with a Zeiss LSM 780 laser scanning confocal microscope using a $20 \times$ objective to capture the entire NMJ-rich muscle area.

Nerve histology and morphometric analysis, and ultrastructural analyses. For nerve histology, after injury (2, 4, and 6 weeks), contralateral and aged sciatic nerves were collected and fixed in $1 \%$ glutaraldehyde, $4 \%$ PFA/0.1 м phosphate buffer, $\mathrm{pH} 7.3$, after which they were postfixed with $1 \%$ osmium tetroxide, dehydrated in acetone, and embedded in Epon LX112 (Ladd Research Industries). Semithin transverse sections of the nerves were stained with toluidine blue and imaged with a Leica histology light microscope using $20 \times$ and $40 \times$ objectives. To evaluate the mean axon count, a $200 \mu \mathrm{m}^{2}$ area was chosen from the center of the sciatic nerve, and the g-ratio (total axon fiber area, including the myelin sheath divided by the area of the axoplasm) was determined on 200230 axons with the help of a g-ratio plug-in (GRatio for ImageJ, RRID: SCR_015580) installed in ImageJ software (National Institutes of Health; ImageJ, RRID:SCR_003070). For the evaluation of axon regeneration, the numbers of remyelinated axons (identified by size, axoplasm content, and condensed myelin) and of axons with degenerated myelin (identified by aberrant myelin morphology) were counted from the same $200 \mu \mathrm{m}^{2}$ area.

For ultrastructural analyses, thin sections of contralateral samples were prepared with Leica Ultracut UCT ultramicrotome, stained in uranyl acetate and lead citrate, and examined with a Tecnai G2 Spirit $120 \mathrm{kV}$ transmission electron microscope (FEI Europe). Images were captured with Veleta and Quemesa CCD cameras using iTEM software (Olympus Soft Imaging Solutions).

Grid hanging test. Static muscle strength was evaluated at 9-10 weeks of age before injury and after injury $(1,1.5,2,3,4$, and 6 weeks after the sciatic nerve crush), or at 52 weeks of age, by placing a mouse on the top of a wire rack $(35 \times 30 \mathrm{~cm}$ with $1 \times 1 \mathrm{~cm}$ grids $)$, slowly inverting the rack and placing it at a height of $30 \mathrm{~cm}$. Latency to fall on padding was recorded over a maximum period of $300 \mathrm{~s}$.

Walking track analysis. Nerve functionality was assessed at 9-10 weeks of age before injury and after injury $(1,1.5,2,3,4$, and 6 weeks after the sciatic nerve crush) by walking track analysis as previously reported (de Medinaceli et al., 1982; Bain et al., 1989; Inserra et al., 1998). Nontoxic ink was brushed on the hindpaws, and prints were obtained on the absorbent side of a piece of bench surface protector paper (VWR) while allowing the mice to walk unassisted along a $5 \times 42 \mathrm{~cm}$ open corridor toward a dark tunnel. Appropriate prints in terms of clarity and readability were chosen for the calculations, and the walk was repeated if necessary to achieve measurable prints. The footprints were analyzed by manual measurement of their length, toe spread, and intermediate toe spread (from the second to the fourth toe) for the control (right) and operated (left) limb. Finally, the sciatic function index (SFI) was calculated using the formula described previously (Bain et al., 1989). The SFI score was considered normal if it lay $\sim-10$, whereas scores $\sim-90$ were taken to indicate total impairment.

Rotarod and beam walking tests. The Rotarod test was performed as previously reported (Rasi et al., 2010). Briefly, mice were placed on a rod of diameter $2 \mathrm{~cm}$ (Ugo Basile) for $30 \mathrm{~s}$, after which the rod was rotated at an accelerating speed from 5 to $19 \mathrm{rpm}$ for up to $8 \mathrm{~min}$ and the latency to fall was recorded. In the beam walking test, also described by Rasi et al. (2010), mice were allowed to walk along a $1 \mathrm{~m}$ rectangular beam at a height of $40 \mathrm{~cm}$ and composed of 3.5-, 2.5-, 1.5-, and 0.5-cm-wide segments from an open platform toward a closed goal in a well-lit room. The number of hindlimb slips and the time taken to cross the beam were recorded. The test was performed after a weekend, and mice had had two training sessions on two separate days during the previous week.

Elevated plus maze. A maze with two closed and two open arms, each $30 \mathrm{~cm} \times 5 \mathrm{~cm}$ in size, was raised to a height of $50 \mathrm{~cm}$ from the floor by means of a lever in a dim room. Mice were placed separately at the center of a platform facing an open arm and allowed to explore the maze for 5 min. A video camera hanging from the ceiling recorded the session for later offline analysis. To assess exploratory activity and anxiety, the numbers of visits to closed or open arms and the times spent there were calculated afterward from a video recording using EthoVision XT 7 software as previously published (Koivisto et al., 2016). A large amount of time spent in the open arms relative to the closed arms is regarded as indicative of reduced anxiety.

Marble burying test. Nine marbles $1 \mathrm{~cm}$ in diameter were placed in a $3 \times 3$ array on the bedding of the home cage. Those visible after $24 \mathrm{~h}$ were counted to evaluate general housekeeping activity and neophobia, as previously reported (Koivisto et al., 2016). A high number of uncovered marbles was taken to indicate reduced anxiety.

von Frey filaments for tactile sensitivity and the hotplate test for pain threshold. Custom-made von Frey hairs were used to test the tactile threshold of the hindpaw. Monofilaments of different length $(3-7 \mathrm{~cm})$ and thickness glued to a wooden spatula $(1 \times 15 \mathrm{~cm})$ were calibrated to correspond to weights of 2.0, 2.8, 3.2, 3.8, 4.3, 4.7, 5.5, 6.2, and 7.0 g. Mice were placed on a $1 \times 1 \mathrm{~cm}$ grid in an upside-down cage to adjust to the test environment for $30 \mathrm{~min}$. The filaments were then tested in ascending order until the mouse no longer reacted to the touch, and the threshold was then reinvestigated in descending order. A hotplate with a surface temperature of $47^{\circ} \mathrm{C}$ and $51^{\circ} \mathrm{C}$ was used to test the pain threshold. The time elapsing before licking a paw was recorded using $60 \mathrm{~s}$ as a cutoff. Each mouse was tested with both temperatures three times at $1 \mathrm{~h}$ intervals (Rasi et al., 2010).

Catwalk gait analysis. An automated gait test and analysis system (CatWalk; Noldus Information Technology) was used to assess changes in spontaneous locomotion. The CatWalk itself features a red overhead lamp and a green illuminated walkway of glass, which measures the pressure of the animal's weight and obtains live footprint videos. The mice were first placed at the open end of the walkway and allowed to walk across it to the darkened escape enclosure. A minimum of three valid runs was obtained for each subject. The variables analyzed included stride length, swing and standing times separately for each paw, and the base of support for both the forepaws and hindpaws.

Nerve conduction and repetitive stimulation studies. Sensory and motor nerve conduction velocity and repetitive stimulation studies were performed as previously published (Latvanlehto et al., 2010). Briefly, 68week-old wild-type and Coll3a1 ${ }^{-1}$ - female mice were anesthetized with $30 / 2.5 \mathrm{mg} / \mathrm{kg}$ ketamine/xylazine, and their body temperature was controlled at $32^{\circ} \mathrm{C}$. Platinum subdermal EEG electrodes $(12 \mathrm{~mm}, 0.4 \mathrm{~mm}$ diameter; Nicolet Biomedical) were used for the recordings and stimulation and surface electrodes for the repetitive stimulation studies, all of which were performed with a Keypoint Portable device (Medtronic).

Compound muscle potentials were recorded subcutaneously from the plantar flexor muscles in the sciatic-tibial motor nerve studies. A distal electrode in the foot pad served as a reference and a surface electrode around the tail as a ground. The $0.04 \mathrm{~ms}$ square pulses were used for nerve stimulation, supramaximal stimulation being given for the maximum response. Latency was measured from the initial onset to the maximum negative peak and amplitude from peak to peak. Motor conduction velocity was calculated as the distance divided by the difference 
between the proximal and distal latencies. The tibial nerve was stimulated at the sciatic notch and at the ankle. F latency was determined by means of stimulation at the knee, tail motor latency distally along the tail at a distance of $3 \mathrm{~cm}$, and sensory nerve conduction velocity proximally along the tail at a $3 \mathrm{~cm}$ distance.

To determine neurotransmission at the NMJ, the sciatic nerve was stimulated at $3 \mathrm{~Hz}$ at the sciatic notch and compound muscle potentials from lateral gastrocnemius muscle were recorded using surfacerecording electrodes placed above the muscle and the reference in the foot pad. The maximum decrement was determined between the second and fifth compound muscle potentials after stimulation.

Histochemistry. For histochemistry, cryosections of the soleus and EDL muscles were taken from before injury and 6 weeks after injury, and aged mice, cut and then stained with H\&E. Samples were imaged with a Leica histology light microscope using $20 \times$ and $40 \times$ objectives to examine muscle fiber regeneration. The muscle fiber area was determined using Image J $1.48 \mathrm{~V}$ software.

Experimental design and statistical analyses. Normality of distribution was tested by using a Kolmogorov-Smirnov, Shapiro-Wilk, or D'AgostinoPearson (Omnibus K2) test depending on a group size. Statistical analyses were performed using the unpaired $t$ test, Mann-Whitney test, or monovariate ANOVA followed by the Bonferroni post hoc test (for normally distributed data) or the Kruskal-Wallis test (for non-normally distributed data) with correction for multiple comparisons using the Benjamin-Hochberg procedure. All data were analyzed with Prism 7 software (GraphPad, RRID:SCR_002798). A $p$ value $\leq 0.05$ was considered statistically significant. Data are calculated mouse-wise $(N=3-15 /$ analysis) if not otherwise indicated and shown as mean \pm SEM.

\section{Results}

\section{NMJ morphology is impaired but not deteriorated further in aged Col13a1 ${ }^{-1-}$ mice}

Previous studies have shown that collagen XIII deficiency results in delayed and incomplete NMJ maturation in mice, combined with changes in muscle fiber type distribution, atrophy, and myasthenia, resembling the muscle pathology observed in CMS19 patients (Latvanlehto et al., 2010; Logan et al., 2015; Härönen et al., 2017). We first assessed here whether collagen XIII expression at NMJs remains unaltered during aging, and then whether the disease is progressive. Our previous analysis of three types of muscle in young Col13a1 ${ }^{-1-}$ mice, including the respiratory muscle diaphragm, the slow-twitch soleus muscle, and the fasttwitch EDL muscle, revealed an alteration in fiber type distribution, and also atrophy, especially in the soleus (Härönen et al., 2017). Hence, we stained the slow-twitch soleus muscles of wildtype and Coll3a1 ${ }^{-1-}$ mice at 64 weeks of age for collagen XIII together with $\alpha$-BTX to locate AChRs. As expected, no staining was detected in the aged Coll3a1 ${ }^{-1-}$ mice (Fig. $1 A$ ), but collagen XIII was detected at the NMJs in their wild-type counterparts, with a pattern similar to that found in 8- to 12-week-old young adults (Latvanlehto et al., 2010; Härönen et al., 2017).

To visualize the nerves at the NMJs, we crossbred the wildtype and Col13a1 ${ }^{-1-}$ mice with Thy-1/YFP transgenic marker mice (Feng et al., 2000), whereupon the sharp-edged AChRs clusters in the soleus of the 64 -week-old wild-type mice (Fig. $1 B$, open arrowheads) were fully innervated, as shown by the YFP expression in the nerves (Fig. $1 B$, merged $\alpha$-BTX and YPF staining). In contrast, the AChR clusters in the age-matched Col13a1 ${ }^{-1-}$ mice were small and fragmented in appearance, and their borders were blurred (Fig. 1B, closed arrowheads). Moreover, the nerves did not extend to cover the entire endplate, so that the receptor clusters were partially naked (Fig. $1 B$, arrows in merged $\alpha$-BTX and YPF staining), resembling the findings in the young adults (Latvanlehto et al., 2010; Härönen et al., 2017). The NMJs were thus impaired in the aged Coll3a1 ${ }^{-1-}$ mice relative to age- matched wild-type mice, and yet the phenotypical changes were not markedly worse than those observed in the NMJs of young adult Col13a1 ${ }^{-1-}$ mice (Latvanlehto et al., 2010; Härönen et al., 2017).

Histology of the soleus muscle in the aged Col13a1 $1^{-1-}$ mice revealed moderate signs of regeneration, both at 64 and 90 weeks of age, as indicated by variations in fiber size and an increased number of centrally located nuclei (Fig. $1 C$, arrows). Quantification confirmed that the mean muscle fiber size was reduced by $\sim 20 \%$ and the number of central nuclei increased approximately threefold to fourfold in the aged Col13a1 ${ }^{-1-}$ mice relative to the aged-matched wild-type mice (Fig. $1 D, E$ ). These alterations do not, however, even at 90 weeks of age, differ significantly from those previously found in the collagen XIII-deficient mice at 12 weeks of age (Härönen et al., 2017). We can therefore conclude that the soleus muscle architecture does not deteriorate further in aged collagen XIII knock-out mice, at least not before 90 weeks of age, as it is comparable with young adult mice.

\section{Muscle function is impaired and permanently altered in aged Col13a1 ${ }^{-1-}$ mice}

We next studied the sciatic nerve morphology of the 64-week-old mice using toluidine blue staining of semithin sections and observed both normal axon fibers in the aged Col13a1 ${ }^{-/-}$mice and marked degeneration of some of the myelinated large-diameter axon fibers (Fig. $1 F$, asterisks). To assess whether such changes have any impact on nerve function, we performed nerve conduction studies on the aged mice. However, these revealed only subtle changes between the genotypes, and none of the sensory or motor parameters of the aged Coll3a1 ${ }^{-1-}$ mice differed significantly from those of the age-matched wild-type individuals (Table 1). In other words, the results resembled those of a similar analysis performed on young adult mice (Latvanlehto et al., 2010). Furthermore, behavioral somatosensory tests on 52-weekold Col13a1 ${ }^{-1-}$ mice suggested normal sensory nerve function, except for a compromised response to mechanical nociception in the Col13a1 ${ }^{-1-}$ females (Table 2).

Because repetitive nerve stimulation of 12 -week-old mice had revealed a true decline in compound muscle action potential in only 1 of 12 collagen XIII knock-out mice (Latvanlehto et al., 2010), we performed the same experiment on 5 aged wild-type and Col13a1 $1^{-1-}$ mice to explore whether the decrease would be more prevalent in old collagen XIII-deficient mice. This was not the case, however, as we found no significant decrease among the 5 mutant mice, implying no further deterioration in the repetitive nerve stimulation experiment (Table 1 , comparison of the amplitude of the fifth peak in compound muscle action potential with that of the second peak).

Nevertheless, the static muscle strength of the aged mice was significantly compromised ( $164.0 \pm 38.2 \mathrm{~s}$ for females, $p=0.021$; and $76.7 \pm 21.6 \mathrm{~s}$ for males, $p=0.002$ ) relative to that of the aged wild-type individuals (cutoff time $300.0 \pm 0.0 \mathrm{~s}$ for both genders) when analyzed using the grid hanging test (Table 2). Furthermore, motor coordination was also significantly impaired in the aged Col13a1 ${ }^{-1-}$ male mice, as they slipped on the horizontal beam more often $(8.0 \pm 1.3$ for females, $p=0.249$; and $9.8 \pm 0.9$ for males, $p=0.001)$ than did the age-matched controls (5.7 \pm 1.3 for females and $3.5 \pm 1.1$ for males; Table 2). Moreover, automated gait analysis (Catwalk) revealed a locomotor defect; the swing time of the hind limbs being significantly shortened $\left(0.10 \pm 0.00 \mathrm{~s}\right.$ for the Coll3a1 ${ }^{-1-}$ mice, $0.14 \pm 0.02 \mathrm{~s}$ for the wild-type mice, $p=0.0005$; Table 3$)$, although the standing time remained normal $\left(0.25 \pm 0.07 \mathrm{~s}\right.$ for the Col13a1 ${ }^{-1-}$ mice, $0.21 \pm$ 
A
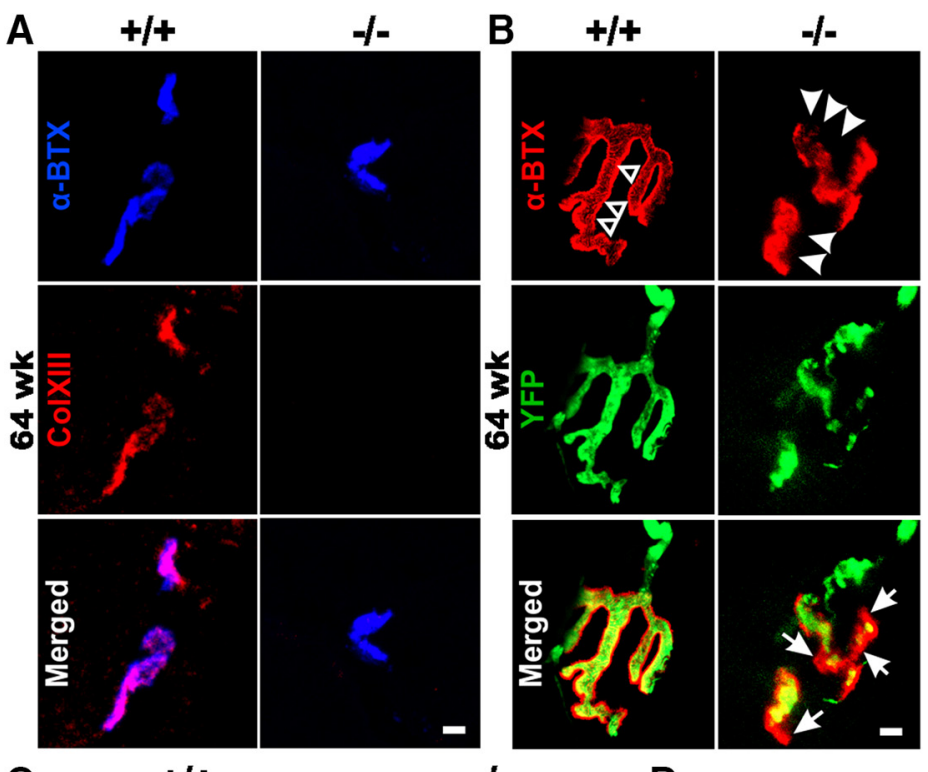

C
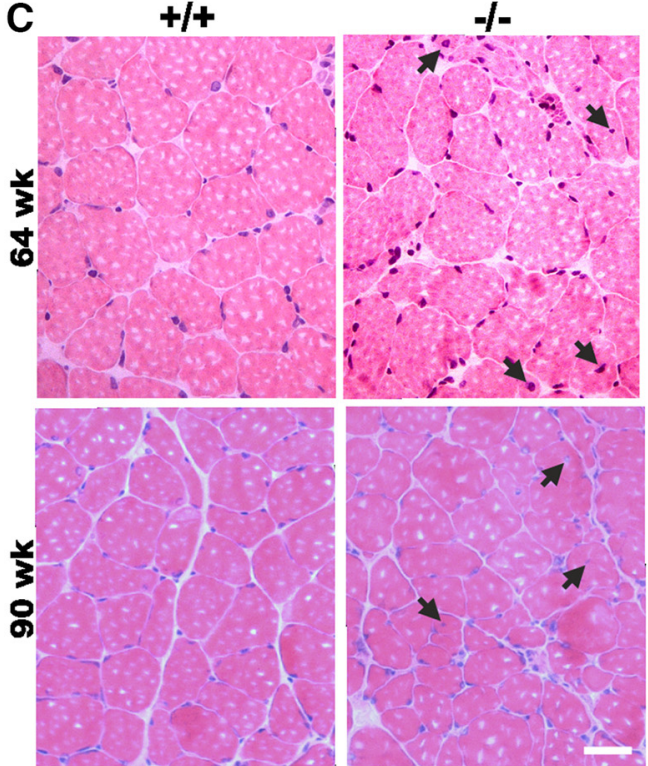

D
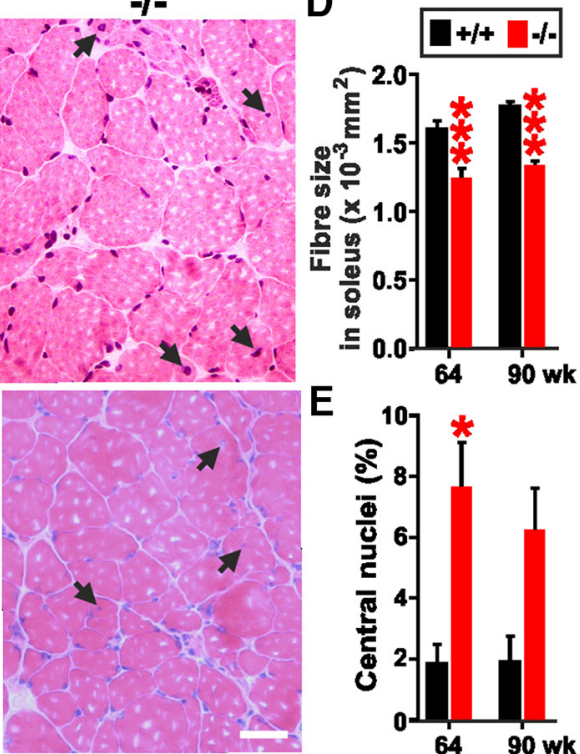

E

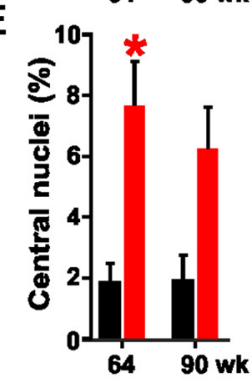

$\mathbf{F}$
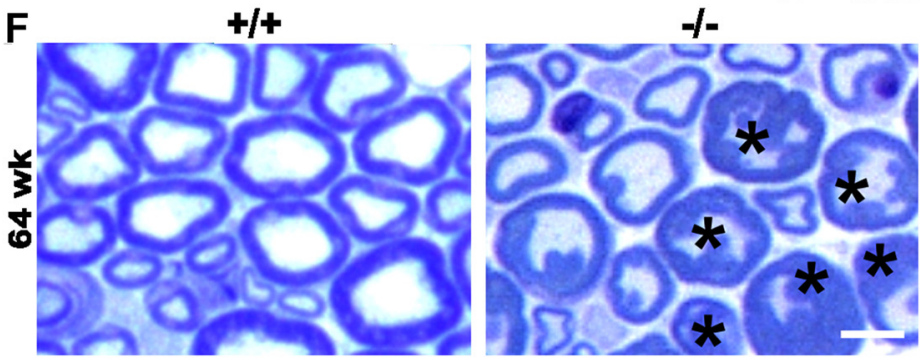

Figure 1. NMJ, muscle, and nerve morphology is altered but stabilized in aged Col13a1 ${ }^{-1-}$ mice. $A$, Immunofluorescent confocal images of frozen cross-sections from the soleus of aged (64 weeks) wild-type $(+/+)$ and $\mathrm{Col} 13 \mathrm{a} \mathrm{1}^{-1}-$ mice $(-/-)$ colabeled with an anti-collagen XIII/NC3 antibody (ColXIII, red) and $\alpha$-BTX (blue) to show AChR clusters. B, Immunofluorescent confocal images of NMJs in the whole-mount-stained soleus of aged wild-type and $\mathrm{Col}_{1331^{-1-}}$ mice. AChRs are stained with $\alpha$-BTX (red), and nerves are fluorescent with YFP marker (green). AChR clusters with sharp edges or diffuse borders are shown by open and closed arrowheads, respectively. Arrows indicate the AChR area lacking nerve terminals. Scale bar, $10 \mu \mathrm{m}$. C, Histology of cross-sections of the soleus muscle in aged and 64- and 90-week-old wild-type and Col13a1 ${ }^{-1}$ - mice stained with H\&E. Arrows indicate muscle fibers with central nuclei. Scale bar, $20 \mu \mathrm{m}$. D, E, Quantification of muscle fiber size at 64 and 90 weeks of age $(p<0.0001 ; p<0.0001)(\boldsymbol{D})$ and proportion of centralized nuclei $(p=0.022 ; p=0.055)(\boldsymbol{E})$. Significances between the wild-type (black) and Col13a ${ }^{-1-}$ mice (black), calculated by unpaired $t$ test or Mann-Whitney test, are shown with red asterisks above the columns. $N=3$ mice/genotype; $n=180-616$ muscle fibers, calculated fiber-wise $(\boldsymbol{D})$ and $n=$ 39-246 fibers/mouse $(\boldsymbol{E})$. $\boldsymbol{F}$, Histology of transversal semithin sciatic nerve sections stained with toluidine blue in aged wild-type and Col13a1 ${ }^{-1-}$ mice. Asterisks indicate degenerated axons. Scale bar, $20 \mu \mathrm{m} .{ }^{*} p \leq 0.05,{ }^{* * *} p \leq 0.001$.
$0.02 \mathrm{~s}$ for the wild-type mice, $p=0.183$; Table 3). This indicates that the aged Coll3a1 ${ }^{-1-}$ mice took shorter and faster steps than the wild-type mice. In addition, the stride length of the hind limbs was reduced $\left(4.47 \pm 0.60 \mathrm{~cm}\right.$ for the Col13a1 ${ }^{-1-}$ mice, $5.43 \pm 0.35 \mathrm{~cm}$ for the wild-type mice, $p=0.007$ ), as was the support width of the front paws $(1.27 \pm 0.15 \mathrm{~cm}$ for the Coll3a1 ${ }^{-1-}$ mice, $1.54 \pm 0.11 \mathrm{~cm}$ for the wild-type mice, $p=0.006$; Table 3 ), suggesting that the functioning of the hind limbs had deteriorated but not that of the forelimbs. Thus, the muscle atrophy and switch in muscle fiber type reported earlier for young adult knock-out mice (Härönen et al., 2017) appear to affect the hind limbs more than the front limbs.

We also analyzed whether collagen XIII deficiency affects emotional behavior because the Col13a1 ${ }^{-1-}$ mice appeared to be more nervous upon handling than were their littermate controls. In practice, however, the 52-week-old Col13a1 ${ }^{-1-}$ mice showed less signs of anxiety in the plus maze (time spent in the closed arms: $3.1 \pm 0.7 \mathrm{~min}$ for the Col13a1 $1^{-1-}$ females and $4.6 \pm 0.1 \mathrm{~min}$ for the wild-type, $p=0.005$; and $3.9 \pm 0.4 \mathrm{~min}$ for the Col13a1 ${ }^{-1-}$ males and $3.7 \pm 0.3 \mathrm{~min}$ for the wild-type, $p=0.255$; Table 3 ) and marble burying tests $(7.6 \pm 1.0$ uncovered marbles for the Col13a1 ${ }^{-1-}$ females and $6.1 \pm 1.4$ for the wild-type, $p=0.413$; and $6.0 \pm 1.1$ for the Coll3a1 ${ }^{-1-}$ males and $3.0 \pm 0.6$ for the wild-type, $p=0.036$; Table 2).

Expression of collagen XIII at the NMJs is dynamic in the course of NMJ regeneration after sciatic nerve injury We next considered the importance of collagen XIII in regeneration following peripheral nerve injury. In addition to the wild-type and Col13a1 ${ }^{-1-}$ mice, these experiments were performed with a Col13a1 $1^{\mathrm{tm} / \mathrm{tm}}$ line that lacked the ability to shed collagen XIII (Härönen et al., 2017). All the mice were crossbred with the Thy-1/YFP marker line to visualize the nerves. We performed the sciatic nerve crush experiment on 9- to 10week-old wild-type, Coll3a1 ${ }^{\mathrm{tm} / \mathrm{tm}}$, and Coll3a1 ${ }^{-1-}$ male mice and stained the soleus muscle for collagen XIII before injury and at 2, 3, 4, and 6 weeks after injury (Fig. $2 A-C)$. A diffuse collagen XIII staining pattern was observed in the wild-type muscle during NMJ regeneration after sciatic nerve injury, especially at 2, 3, and 4 weeks after injury (Fig. 2A), and at 6 weeks after injury a spot-like pattern appeared, resembling the collagen XIII expression pattern demonstrated previously (Latvanlehto et al., 2010; Härönen et al., 2017). In the Col13a1 ${ }^{\mathrm{tm} / \mathrm{tm}}$ 
Table 1. Nerve conduction and repetitive stimulation studies on 68-week-old wild-type and Col13a1 ${ }^{-/-}$female mice ${ }^{a}$

\begin{tabular}{|c|c|c|c|c|c|}
\hline Nerve & Type & Parameter & $\begin{array}{l}\text { Coll3a1 }^{+/+} \\
(N=5) \\
(\text { mean } \pm \text { SEM })\end{array}$ & $\begin{array}{l}\text { Coll3a1 }^{-l-} \\
(N=5) \\
(\text { mean } \pm \text { SEM) }\end{array}$ & $p$ \\
\hline \multirow[t]{4}{*}{ Tail } & \multirow[t]{2}{*}{ Sensory } & $\mathrm{SCV}(\mathrm{m} / \mathrm{s})$ & $40.8 \pm 0.9$ & $35.6 \pm 1.9$ & 0.095 \\
\hline & & $\operatorname{SNAP}(\mu \mathrm{V})$ & $410.8 \pm 54.5$ & $429.6 \pm 39.0$ & 0.786 \\
\hline & \multirow[t]{2}{*}{ Motor } & Latency (ms) & $0.8 \pm 0.0$ & $0.9 \pm 0.0$ & 0.056 \\
\hline & & Amplitude (mV) & $0.3 \pm 0.0$ & $0.2 \pm 0.0$ & 0.444 \\
\hline \multirow[t]{5}{*}{ Tibial } & \multirow[t]{5}{*}{ Motor } & $\mathrm{MCV}(\mathrm{m} / \mathrm{s})$ & $36.6 \pm 1.4$ & $34.9 \pm 3.3$ & 0.660 \\
\hline & & Latency (ms) & $1.4 \pm 0.0$ & $1.6 \pm 0.1$ & 0.117 \\
\hline & & CMAP 1 (mV) & $6.2 \pm 1.8$ & $3.4 \pm 0.9$ & 0.195 \\
\hline & & CMAP 2 (mV) & $7.1 \pm 1.6$ & $5.4 \pm 1.9$ & 0.522 \\
\hline & & F-latency (ms) & $5.7 \pm 0.1$ & $6.1 \pm 0.1$ & 0.056 \\
\hline \multirow[t]{2}{*}{ Ischial } & \multirow[t]{2}{*}{$\begin{array}{l}\text { Motor } \\
\quad \text { response }\end{array}$} & Latency (ms) & $1.7 \pm 0.1$ & $1.8 \pm 0.0$ & 0.206 \\
\hline & & Amplitude (mV) & $59.3 \pm 7.1$ & $56.3 \pm 9.8$ & 0.808 \\
\hline Ischial & $\begin{array}{c}\text { Repetitive } \\
\text { (3 Hz) }\end{array}$ & $\begin{array}{l}\text { CMAP change } \\
\text { (5th/2nd; \%) }\end{array}$ & $+3.0 \pm 0.4$ & $+3.4 \pm 1.1$ & 0.572 \\
\hline
\end{tabular}

${ }^{a} \mathrm{SCV}$, Sensory conduction velocity; MCV, motor conduction velocity; SNAP, sensory nerve action potential; CMAP 1 , mean compound action potential with stimulation at the sciatic notch; CMAP 2, mean compound action potential with stimulation at the ankle.

Table 2. Compiled results of the behavioral tests on 52-week-old wild-type and Col13a1 ${ }^{-1-}$ mice

\begin{tabular}{|c|c|c|c|c|c|}
\hline Test type & Test & Gender & $\begin{array}{l}\text { Col13a1 }^{+/+} \\
(N=6 \text { or } 7) \\
(\text { mean } \pm \text { SEM })\end{array}$ & $\begin{array}{l}\text { Col13a1 } \\
(N=6 \text { or } 7) \\
(\text { mean } \pm \text { SEM })\end{array}$ & $p$ \\
\hline \multirow[t]{8}{*}{ Motor test } & Grid hanging & Female & $300.0 \pm 0.0$ & $164.0 \pm 38.2$ & $0.021^{*}$ \\
\hline & Time (s) & Male & $300.0 \pm 0.0$ & $76.7 \pm 21.6$ & $0.002^{* *}$ \\
\hline & Rotarod & Female & $300.9 \pm 20.0$ & $300.6 \pm 48.0$ & 0.996 \\
\hline & Time (s) & Male & $283.7 \pm 62.6$ & $230.2 \pm 49.7$ & 0.394 \\
\hline & Beam walking & Female & $21.4 \pm 11.3$ & $14.6 \pm 3.2$ & 0.935 \\
\hline & Time (s) & Male & $18.8 \pm 4.7$ & $22.8 \pm 10.9$ & 0.797 \\
\hline & Beam walking & Female & $5.7 \pm 1.3$ & $8.0 \pm 1.3$ & 0.249 \\
\hline & Slips (no.) & Male & $3.5 \pm 1.1$ & $9.8 \pm 0.9$ & $0.001^{* * *}$ \\
\hline Anxiety & Plus maze & Female & $10.6 \pm 1.4$ & $8.3 \pm 2.1$ & 0.377 \\
\hline \multirow[t]{9}{*}{ Movement } & Visits closed arms (no.) & Male & $13.8 \pm 2.0$ & $12.3 \pm 1.2$ & 0.531 \\
\hline & Plus maze & Female & $0.4 \pm 0.3$ & $1.6 \pm 0.6$ & 0.176 \\
\hline & Visits open arms & Male & $1.7 \pm 0.6$ & $1.0 \pm 0.6$ & 0.314 \\
\hline & Plus maze & Female & $11.0 \pm 1.6$ & $9.9 \pm 1.7$ & 0.626 \\
\hline & Total visits (no.) & Male & $15.5 \pm 2.4$ & $13.3 \pm 1.1$ & 0.431 \\
\hline & Plus maze & Female & $4.6 \pm 0.1$ & $3.1 \pm 0.7$ & $0.005^{* *}$ \\
\hline & Time closed arms (min) & Male & $3.7 \pm 0.3$ & $3.9 \pm 0.4$ & 0.255 \\
\hline & Plus maze & Female & $0.04 \pm 0.03$ & $1.8 \pm 0.6$ & 0.103 \\
\hline & Time open arms (min) & Male & $0.2 \pm 0.1$ & $0.2 \pm 0.2$ & 0.260 \\
\hline \multirow[t]{2}{*}{ Anxiety } & Marble burying & Female & $6.1 \pm 1.4$ & $7.6 \pm 1.0$ & 0.413 \\
\hline & Marbles visible (no.) & Male & $3.0 \pm 0.6$ & $6.0 \pm 1.1$ & $0.036^{*}$ \\
\hline \multirow[t]{6}{*}{ Somatosensory } & von Frey hairs & Female & $3.8 \pm 0.4$ & $4.8 \pm 0.3$ & $0.029^{*}$ \\
\hline & Force $(g)$ & Male & $3.5 \pm 0.3$ & $3.9 \pm 0.5$ & 0.471 \\
\hline & Hot plate $47^{\circ} \mathrm{C}$ & Female & $50.0 \pm 2.5$ & $42.1 \pm 4.0$ & 0.118 \\
\hline & Time (s) & Male & $37.5 \pm 2.4$ & $36.8 \pm 4.9$ & 0.905 \\
\hline & Hot plate $51^{\circ} \mathrm{C}$ & Female & $15.7 \pm 1.0$ & $15.7 \pm 1.0$ & 1.000 \\
\hline & Time (s) & Male & $10.5 \pm 0.5$ & $12.3 \pm 0.7$ & 0.062 \\
\hline
\end{tabular}

${ }^{*} p \leq 0.05 ;{ }^{* *} p \leq 0.01 ;{ }^{* * *} p \leq 0.001$.

line, however, collagen XIII expression remained unaltered throughout the NMJ regeneration process, reflecting the occurrence of only the transmembrane form of the protein and no shed protein (Fig. 2B). As expected, no collagen XIII staining was detected in the Coll3a1 ${ }^{-1-}$ mice (Fig. 2C).

To correlate the changes in muscle weight during recovery from the peripheral nerve injury, we first measured the body weights of the wild-type, Col13a1 $1^{\mathrm{tm} / \mathrm{tm}}$, and Col13a1 ${ }^{-1-}$ mice. The mean body weight of the Col13a1 ${ }^{-1-}$ mice on postnatal days 63-70 (P63-P70), at the time of starting the nerve crush experi-
Table 3. Gait analysis of 52-week-old wild-type and Col13a1 ${ }^{-/-}$male mice

\begin{tabular}{llllll}
\hline Test type & Test & Limb & $\begin{array}{l}\text { Col13a1 } \\
(N=6 \text { or } 7) \\
(\text { mean } \pm \text { SEM) }\end{array}$ & $\begin{array}{l}\text { Col13a1 } \\
(N=6 \text { or } 7) \\
(\text { mean } \pm \text { SEM) }\end{array}$ & $p$ \\
\hline Catwalk & Swing duration & Front & $0.14 \pm 0.01$ & $0.14 \pm 0.02$ & 0.513 \\
& Time $(s)$ & Hind & $0.14 \pm 0.02$ & $0.10 \pm 0.00$ & $0.0005^{* * *}$ \\
& Stand duration & Front & $0.22 \pm 0.03$ & $0.26 \pm 0.05$ & 0.176 \\
& Time (s) & Hind & $0.21 \pm 0.02$ & $0.25 \pm 0.07$ & 0.183 \\
& Stride length & Front & $5.78 \pm 0.45$ & $5.29 \pm 0.63$ & 0.180 \\
& Length (mm) & Hind & $5.43 \pm 0.35$ & $4.47 \pm 0.60$ & $0.007^{* *}$ \\
& Support width & Front & $1.54 \pm 0.11$ & $1.27 \pm 0.15$ & $0.006^{* *}$ \\
& Width $(\mathrm{cm})$ & Hind & $2.29 \pm 0.10$ & $2.40 \pm 0.21$ & 0.281 \\
\hline
\end{tabular}

${ }^{* *} p \leq 0.01 ;{ }^{* * *} p \leq 0.001$.

ment, was significantly reduced by $8 \%$ relative to the wild-type mice, the difference between the genotypes remaining stable throughout the experiment, whereas the Col13al $1^{\mathrm{tm} / \mathrm{tm}}$ mice did not differ from the controls (Fig. 2D). We then normalized the weights of the soleus and EDL muscles, slow- and fast-dominant types, respectively, with the body weight. The Col13a1 ${ }^{-1-}$ soleus muscle was found to be atrophic because its relative preinjury weight was significantly reduced by $33 \%$ (Fig. 2E), whereas that of the EDL muscle did not differ from the situation in the wild-type (Fig. $2 F$ ), a distinction between muscle types that is in line with previous findings (Härönen et al., 2017). Peripheral nerve injury induced a significant reduction in the normalized EDL weight in all the genotypes, whereas the same relation was observed in the soleus muscle only in the Col13a1 ${ }^{-1-}$ mice, where the muscle weight was significantly reduced by $31 \%$ at 2 weeks and $26 \%$ at 3 weeks after injury relative to the preinjury value, suggesting that the nerve injury caused more devastating damage of this muscle in the Coll3a1 ${ }^{-1-}$ mice than in the wild-type, where the corresponding reduction in muscle weight was only $\sim 4 \%$ at 2 and 3 weeks after injury (Fig. 2E). The soleus muscle in the Col13a1 ${ }^{-1-}$ mice was slowly recovering, although its weight was still slightly reduced by $11 \%$ at the end of the follow-up period (i.e., at 6 weeks after injury) relative to the preinjury situation (Fig. 2E). The EDL in the Col13a1 ${ }^{-1-}$ mice recovered in the same way as in the wild-type (Fig. $2 F$ ), as did both the soleus and EDL in the Col13a $1^{\mathrm{tm} / \mathrm{tm}}$ mice (Fig. 2E,F). Based on these observations, it is evident that collagen XIII plays an important role during NMJ regeneration after peripheral nerve injury, especially in the soleus muscle, which is already atrophic in Col13a1 ${ }^{-1-}$ mice before injury (Fig. 2E).

NMJ morphology and regeneration after sciatic nerve injury are severely impaired and incomplete in the soleus muscle of Coll3a1 ${ }^{-1-}$ mice

To evaluate the manner in which the lack of collagen XIII impairs NMJ morphology and regeneration after sciatic nerve injury, we performed nerve crush experiments on wild-type, Col13a $1^{\mathrm{tm} / \mathrm{tm}}$, and Coll3a1 ${ }^{-1-}$ mice, collected preinjury and postinjury samples, and imaged whole-mount preparations of the soleus (Fig. $3 A$ ) and EDL muscles (Fig. $4 A$ ) for examination of YFP expression in presynaptic axons and Alexa-594-conjugated $\alpha$-BTX labeling of postsynaptic AChRs. Four parameters were quantified to evaluate NMJ regeneration after nerve injury: fully innervated NMJs, where a nerve terminal is exactly opposed to AChRs (Figs. $3 A b, B$, $4 A, B)$; partially innervated NMJs, where AChRs are erroneously or not fully innervated by an axon terminal (Figs. $3 A c, C, 4 A, C$ ); NMJs with terminal sprouting, where a nerve grows beyond the $\mathrm{AChR}$ area and may or may not find another synaptic site (Figs. $3 A d, D, 4 A, D$ ); and denervated NMJs, where the AChRs 
A

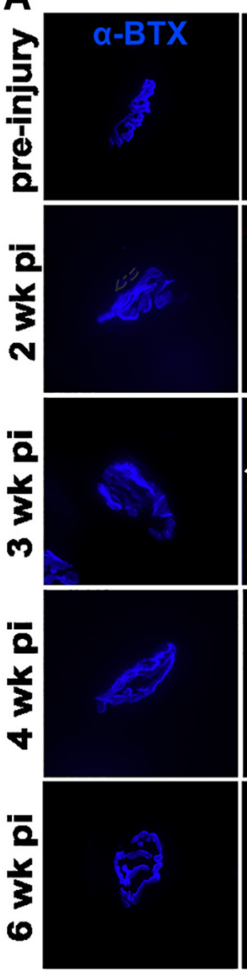

C
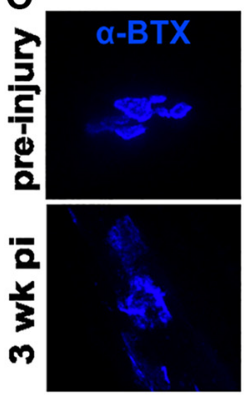

E
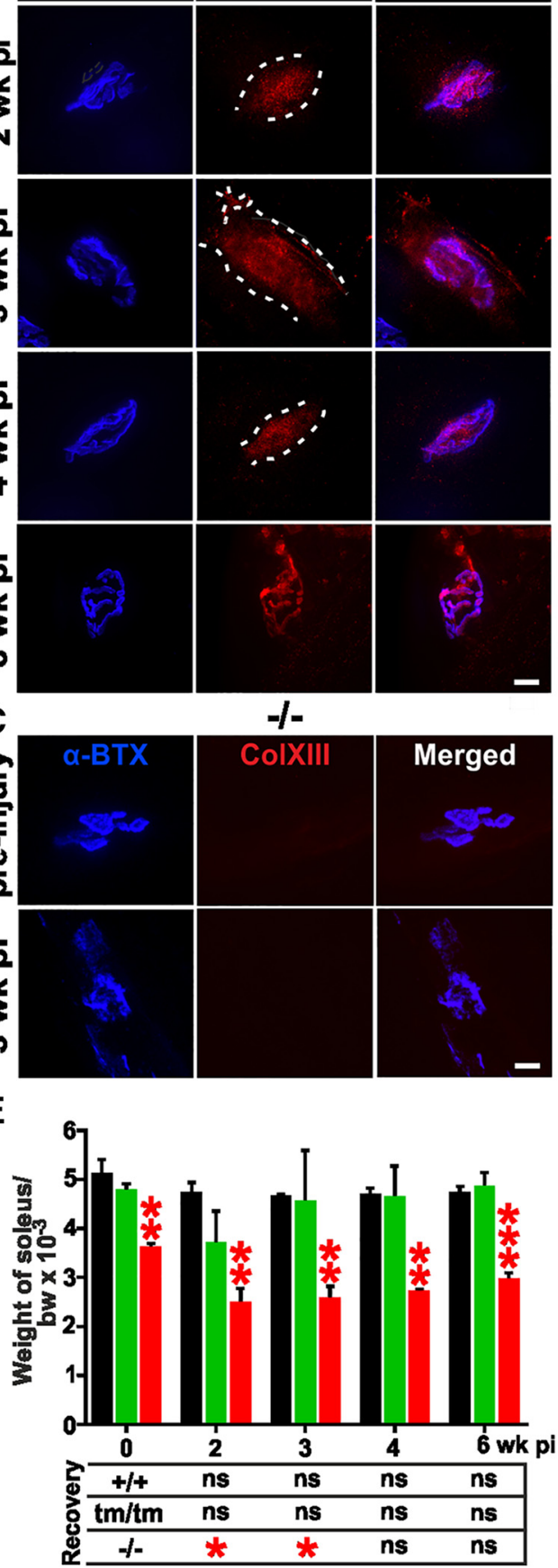

$-1-$
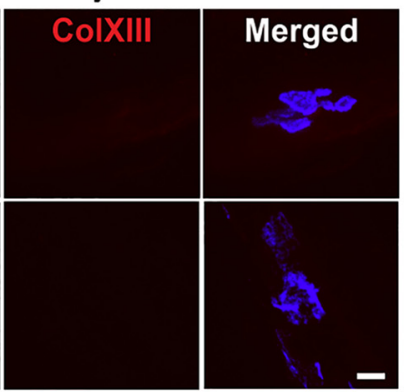

B
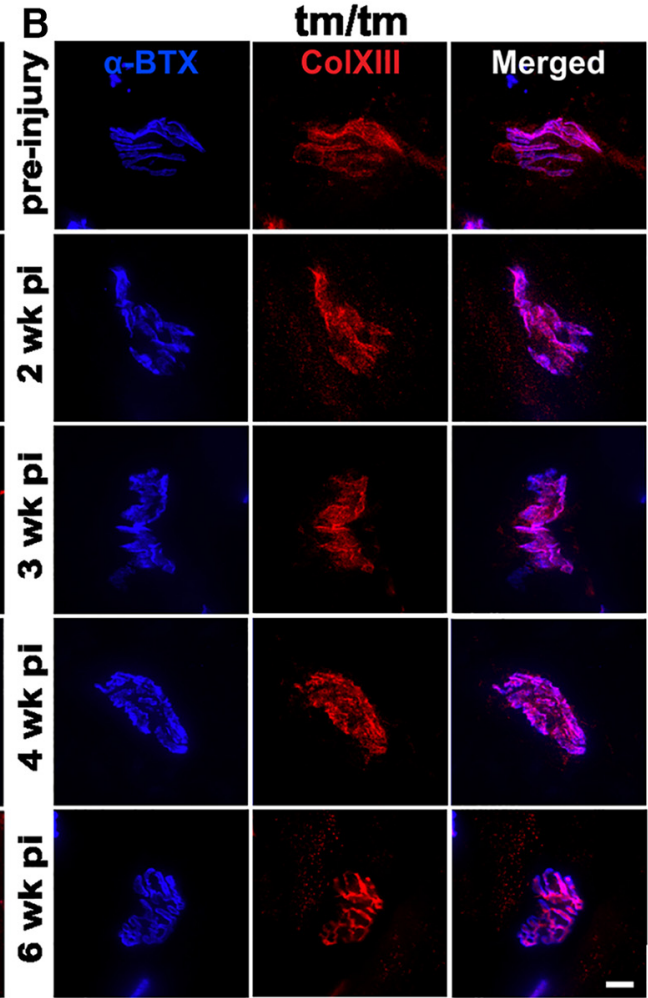

D

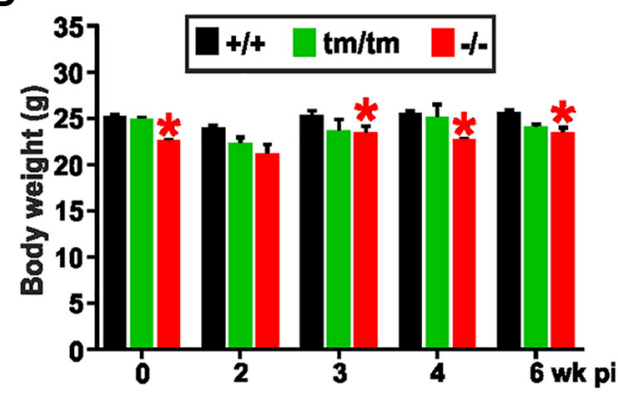

F

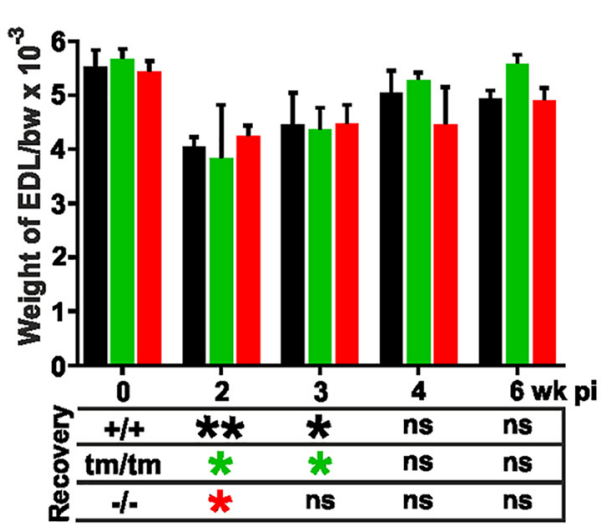

Figure 2. Dynamic expression of collagen XIII at the NMJ and affected body and soleus weigth in Co/13a ${ }^{-1-}$ mice during postinjury NMJ regeneration. $A-C$, Immunofluorescent confocal images of NMJs in the soleus of wild-type $(+/+; \boldsymbol{A}), \mathrm{Col} 13 a 1^{\mathrm{tm} / \mathrm{tm}}(\mathrm{tm} / \mathrm{tm} ; \boldsymbol{B})$, and $\mathrm{Col} 13 a 1^{-1-}(-/-; \boldsymbol{C})$ mice before injury and at $2,3,4$, and 6 weeks after injury (post injury; pi), colabeled with an anti-collagen XIII/NC3 antibody (red) and $\alpha$-BTX (blue) to show AChR clusters. Scale bar, $10 \mu \mathrm{m}$. $\boldsymbol{A}$, White hyphenated lines indicate a diffused staining pattern of collagen XIII. $\boldsymbol{D}-\boldsymbol{F}$, Body weight $(\boldsymbol{D})$ and weight of the soleus muscle $(\boldsymbol{E})$ and EDL $(\boldsymbol{F})$ normalized by body weight (bw) in Col13a $1^{\mathrm{tm} / \mathrm{tm}}$ (green) and Col13a ${ }^{-1-}$ mice (red), relative to the wild-type (black). Body weight of Col13a1 ${ }^{-1-}$ mice before injury and at 3,4 , and 6 weeks after injury $(p=0.005, p=0.028, p=0.011, p=0.032)(\boldsymbol{D})$ and weight of the soleus muscle before injury and at $2,3,4$, and 6 weeks after injury $(p=0.010, p=0.013, p=0.003, p=0.003, p=0.001)(E)$ relative to wild-type mice. Significances at specified time points between the wild-type and Col13a ${ }^{\mathrm{tm} / \mathrm{tm}}$ mice and between the wild-type and Col13a1 $-1-$ mice, calculated by the unpaired $t$ test or the Mann-Whitney test (green and red asterisks above columns, respectively). Significance of the soleus muscle weight in the Col13a1 $-1-$ mice from before injury to 2 and 3 weeks after injury $(p=0.022, p=0.035)(\boldsymbol{E})$. Significance of the EDL muscle weight in the wild-type mice $(p=0.007, p=0.042)$ and $\mathrm{Col13a} 1^{\mathrm{tm} / \mathrm{tm}}$ mice $(p=0.012, p=0.016)$ from before injury to 2 and 3 weeks after injury and in the Col13a ${ }^{-/}$- mice from before injury to 2 weeks after injury $(p=0.023)(\boldsymbol{F})$. Significances over time within the wild-type, Col13a $1^{\mathrm{tm} / \mathrm{tm}}$, and Col13a1 $-1-$ mice, calculated by ANOVA followed by the Bonferroni post hoc test or the Kruskal-Wallis test with correction for multiple comparisons using the Benjamin-Hochberg procedure, are shown in tables below the graphs. $N=3-8$ mice/genotype/time point. ${ }^{*} p \leq 0.05,{ }^{* *} p \leq 0.01,{ }^{* * *} p \leq 0.001$. 
A
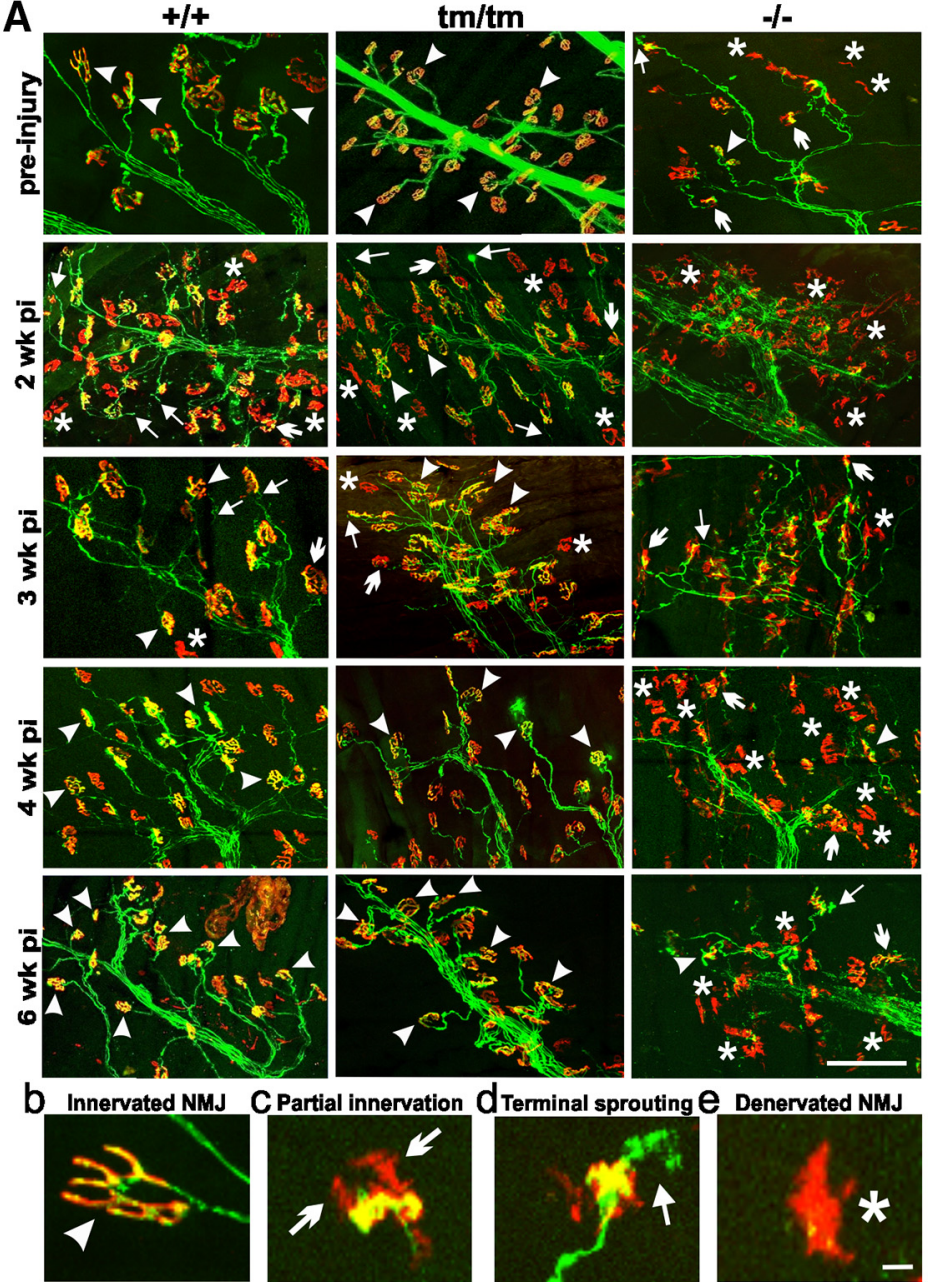

B
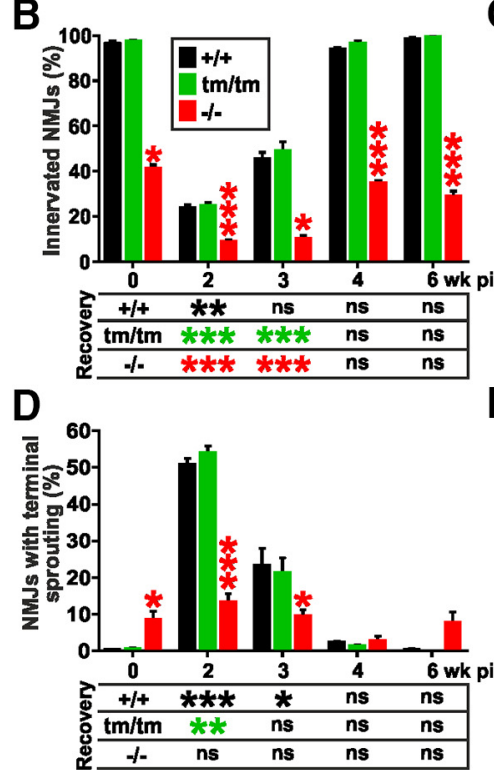

$\mathrm{E}$

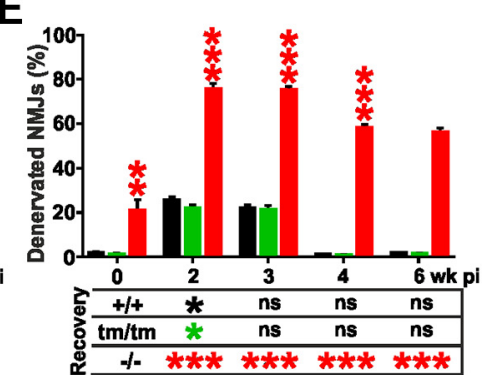

Figure 3. NMJ morphology and regeneration are severely impaired in Col13a ${ }^{-1}$ - mice. $A$, Immunofluorescent confocal images of NMJs in the whole soleus of wild-type, $\mathrm{Col} 13 \mathrm{a} 1^{\mathrm{tm} / \mathrm{tm}}$, and $\mathrm{Col} 13 \mathrm{a} 1^{-1-}$ mice before injury and at 2, 3, 4, and 6 weeks after injury. AChRs were stained with $\alpha$-BTX (red), and nerves were fluorescent with YFP marker (green). Arrowheads indicate innervated NMJ $(\boldsymbol{A} \boldsymbol{b})$. Thick arrows indicate partially innervated NMJ $(\boldsymbol{A c})$. Arrows indicate NMJ with terminal sprouting $(\boldsymbol{A d})$. Asterisks indicate denervated NMJ (Ae). Scale bar, $100 \mu \mathrm{m}$. $\boldsymbol{B}-\boldsymbol{E}$, Numbers of innervated NMJs in the soleus of $\mathrm{Col} 13 a 1^{-1-}$ mice compared with the wild-type before injury and at 2,3,4, and 6 weeks after injury $(p=0.028, p=0.001, p=0.016, p<0.0001$, $p<0.0001)(\boldsymbol{B})$; numbers of partially innervated NMJs before injury and 2 weeks after injury $(p=0.010, p=0.011)(\boldsymbol{C})$; numbers of NMJs with terminal sprouting before injury and at 2 and 3 weeks after injury $(p=0.029, p<0.0001, p=0.019)(\boldsymbol{D})$; and numbers of denervated NMJs before injury and at 2,3,4, and 6 weeks after injury $(p=0.008, p<0.0001, p<0.0001$ completely lack innervation (Figs. 3Ae,E, $4 A, E)$. Wild-type NMJs in the soleus muscle were almost exclusively fully innervated before injury and at the end of the follow-up period, at 6 weeks after injury (Fig. 3B). The number of innervated NMJs in the wild-type mice during regeneration decreased to $25 \%$ at 2 weeks after injury, rising to $47 \%$ at 3 weeks after injury (Fig. $3 B$ ), and the proportion of denervated NMJs increased to $27 \%$ and $25 \%$ at 2 and 3 weeks after injury, respectively, whereas such NMJs hardly existed at all before injury (Fig. 3E). Partially innervated NMJs, one of the important features of an NMJ regeneration process, were 4.1fold at 2 weeks after injury and 4.5-fold at 3 weeks (Fig. 3C) in the wild-type mice, and NMJs with terminal sprouting were markedly increased, accounting for 51\% of all junctions at 2 weeks after injury and $24 \%$ at 3 weeks, whereas such features scarcely existed before injury (Fig. 3D), thereby indicating extensive regeneration in the course of time. NMJ regeneration in the soleus muscle was already fully completed at 4 weeks after injury in the wildtype mice (Fig. $3 B-E$ ), whereas in the Col13a1 ${ }^{-1-}$ mice only $43 \%$ of NMJs were fully innervated before injury, and this proportion decreased further to $9 \%$ at 2 and $10 \%$ at 3 weeks after injury, being $37 \%$ at 4 and $30 \%$ at 6 weeks after injury (Fig. 3B). A typical feature of the soleus muscle in the Col13a1 $1^{-/-}$mice was a

\footnotetext{
$p<0.0001, p<0.0001, p=0.057)(\boldsymbol{E})$. Significances of differences between the wild-type and $\mathrm{Col} 13 \mathrm{a} 1^{-1-}$ mice at specified time points, calculated by the unpaired $t$ test or the Mann-Whitney test (red asterisks above columns). Significance within the genotype of differences in innervated NMJs in the wild-type $(p=0.003$ ) from before injury to 2 weeks after injury, Col13a ${ }^{\mathrm{m} / \mathrm{tm}}(p<0.0001, p<0.0001)$, and Col13a1 $1^{-1-}$ mice $(p=0.001, p=0.0004)$ from before injury to 2 and 3 weeks after injury $(\boldsymbol{B})$; in partially innervated NMJs in the wild-type $(p=0.030, p=0.020)$ and Col13a ${ }^{\mathrm{tm} / \mathrm{tm}}(p<0.0001, p=0.002)$ from before injury to 2 and 3 weeks after injury and in the Col13a ${ }^{-1-}$ mice from before injury to 2,3, and 4 weeks after injury ( $p=0.001, p=$ $0.012, p=0.009)(C)$; in NMJs with terminal sprouting in the wild-type from before injury to 2 and 3 weeks after injury $(p=0.001, p=0.021)$, and Col13a $1^{\mathrm{tm} / \mathrm{tm}}$ mice $(p=0.003)$ from before injury to 2 weeks after injury $(\boldsymbol{D})$; and in denervated NMJs in the wild-type $(p=0.023)$ and Col13a ${ }^{\mathrm{tm} / \mathrm{tm}}$ mice ( $p=0.047$ ) from before injury to 2 weeks after injury and in the $\mathrm{Col}_{1331^{-1}-}$ mice from before injury to 2,3,4, and 6 weeks after injury $(p<0.0001, p<0.0001, p<0.0001$, $p<0.0001)(\boldsymbol{E})$. Significances over time within the wild-type, $\mathrm{Col} 13 \mathrm{a} 1^{\mathrm{tm} / \mathrm{tm}}$, and Col13a1 ${ }^{-1-}$ mice, calculated by ANOVA followed by the Bonferroni post hoc test or the Kruskal-Wallis test with correction for multiple comparisons using the Benjamin-Hochberg procedure, are shown in tables below the graphs. $N=3-5$ mice/genotype/time point; $n=100 \mathrm{NMJ} /$ mouse. ${ }^{*} p \leq 0.05,{ }^{* *} p \leq 0.01,{ }^{* * *} p \leq 0.001$.
}

$\leftarrow$ 

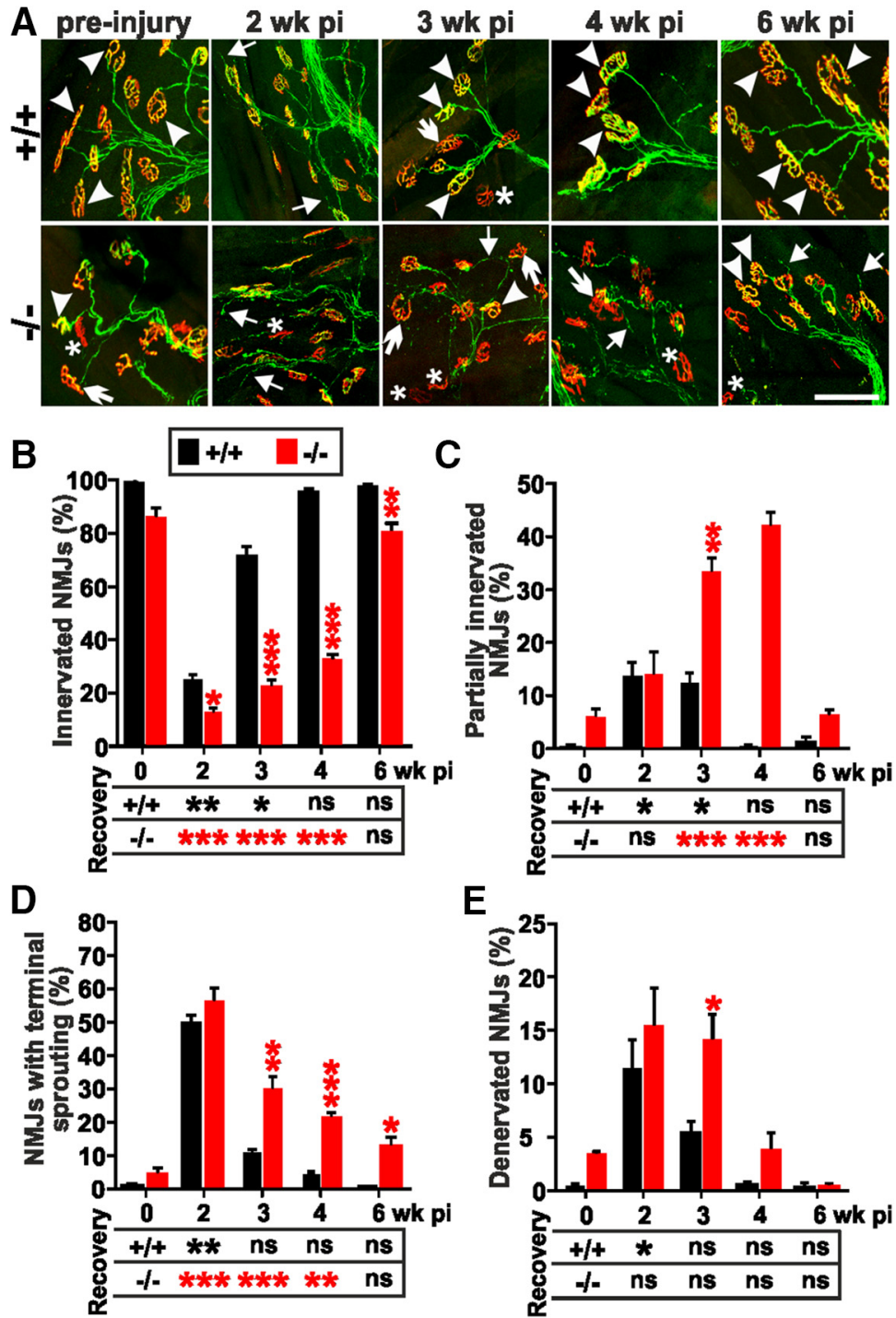

$\mathbf{E}$

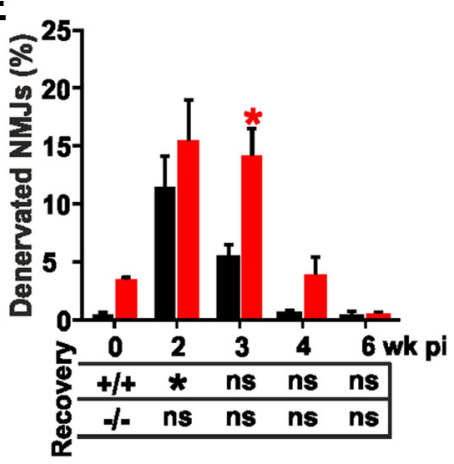

Figure 4. NMJ regeneration is slower, although still complete, in the EDL of Col13a ${ }^{-1-}$ mice. $A$, Immunofluorescent confocal images of NMJs in the EDL of wild-type and Col13a1 ${ }^{-1-}$ mice before injury and at 2,3,4, and 6 weeks after injury. AChRs were stained with $\alpha$-BTX (red), and nerves were fluorescent with YFP marker (green). $\boldsymbol{B}-\boldsymbol{E}$, Numbers of innervated NMJs in the EDL in Col13a1 ${ }^{-1-}$ mice relative to the wild-type at 2, 3, 4, and 6 weeks after injury $(p=0.011, p=0.0004, p<0.0001$, and $p=$ $0.005)(\boldsymbol{B})$; of partially innervated NMJs at 3 weeks after injury $(p=0.003)(\boldsymbol{C})$; of NMJs with terminal sprouting at 3,4 , and 6 weeks after injury $(p=0.008, p=0.001$, and $p=0.011)(\boldsymbol{D})$; and of denervated NMJs at 3 weeks after injury $(p=0.036)(\boldsymbol{E})$. Significances of differences between the wild-type and $\mathrm{Col}_{1331^{-1}}$ mice at specified time points, calculated by the unpaired $t$ test or the Mann-Whitney test, are shown with red asterisks above the columns. Significances of differences in innervated NMJs in the wild-type mice from before injury to 2 and 3 weeks after injury $(p=0.002, p=0.022)$ and in the Col13a ${ }^{-1-}$ mice from before injury to 2,3 , and 4 weeks after injury $(p<0.0001, p<0.0001, p<0.0001)(B)$; in partially innervated NMJs in the wild-type from before injury to 2 and 3 weeks after injury $(p=0.023, p=0.038)$ and in $C o l 13 a 1^{-1-}$ from before injury to 3 and 4 weeks after injury $(p=0.0001, p<0.0001)(C)$; in NMJs with terminal sprouting in the wild-type from before injury to 2 weeks after injury ( $p=0.006)$ and in the Col13a1 ${ }^{-1-}$ mice from before injury to 2,3, and 4 weeks after injury $(p<0.0001, p=0.001$ $p=0.009)(\boldsymbol{D})$; and in denervated NMJs in the wild-type mice from before injury to 2 weeks after injury $(p=0.011)(\boldsymbol{E})$. Significances over time within the wild-type and $\mathrm{Col}_{13} \mathrm{a} 1^{-1-}$ mice, calculated by ANOVA followed by the Bonferroni posthoc test or the Kruskal-Wallis test with correction for multiple comparisons using the Benjamin-Hochberg procedure, are shown in tables below graphs. $N=3$ mice/genotype/time point; $n=100$ NMJs/mouse. ${ }^{*} p \leq 0.05,{ }^{* *} p \leq 0.01,{ }^{* * *} p \leq 0.001$.

greatly increased number of partially innervated NMJs, as they made up $28 \%$ of the NMJs before injury, but, in contrast to the wild-type, their proportion decreased to $4 \%$ at 2 weeks after injury, $7 \%$ at 3 weeks, and $6 \%$ at 4 weeks, increasing again to $9 \%$ at 6 weeks (i.e., still falling significantly short of the preinjury situation; Fig. 3C). Terminal sprouting and denervation was 33-fold and 11-fold more common, respectively, in the soleus of the Col13a1 $1^{-1-}$ mice than in the wild-type before injury (Fig. $\left.3 D, E\right)$.
The peripheral nerve injury induced a highly significant increase in the number of NMJs with terminal sprouting in the wild-type, although this did not significantly change from the preinjury situation in the soleus of the Col13a1 $1^{-1-}$ mice following injury (Fig. 3D). Instead, the injury induced a highly significant increase in the proportion of denervated NMJs, indicating that regeneration was severely delayed and still incomplete at 6 weeks after injury in Col13a1 ${ }^{-1-}$ mice (Fig. $3 E$ ). Forced expression of the transmembrane form alone in the Col13a1 ${ }^{\mathrm{tm} / \mathrm{tm}}$ mice fully restored the capability of the NMJs to regenerate in the soleus muscle within 1 month of the injury (Fig. $3 B-E$ ). Thus, lack of collagen XIII ectodomain shedding does not compromise the regeneration process.

Although the EDL muscle is not atrophic before injury, we nevertheless tested whether the morphology and regeneration of the NMJ following nerve crush are altered in the EDL of Col13a1 $1^{-/-}$mice. Because there were no differences in the soleus of the injured Coll3a $1^{\mathrm{tm} / \mathrm{tm}}$ mice, we analyzed the EDL further only in the wild-type and Col13a1 $1^{-1-}$ mice. In the latter, the NMJs of the EDL possessed a milder phenotype than those in the soleus because $87 \%$ were fully innervated before injury (Fig. 4B). Consistently with this, the preinjury proportion of partially innervated NMJs was much lower in the EDL (Fig. $4 C$ ): only $6 \%$ of the NMJs compared with $28 \%$ in the soleus muscle (Fig. $3 C$ ). Together, the preinjury numbers of fully innervated NMJs, partially innervated NMJs, NMJs with terminal sprouting and denervated NMJs in the Col13a1 ${ }^{-1-}$ mice did not differ significantly from those in the wild-type (Fig. $4 B-E$ ). The NMJs of the EDL in the wildtype mice were almost exclusively fully innervated before injury, whereas this number decreased to $25 \%$ at 2 weeks after injury, rose to $70 \%$ at 3 weeks, and reached almost full innervation at 4 weeks (Fig. 4B). In contrast, innervation was delayed in the Col13a1 $1^{-1-}$ mice, with proportions of $12 \%$ at 2 weeks after injury, $23 \%$ at 3 weeks, $32 \%$ at 4 weeks, and almost reaching the preinjury state at 6 weeks after injury, although still lagging significantly behind the wild-types (Fig. 4B). Regeneration took more time in the EDL of the Col13a1 ${ }^{-1-}$ mice than in the wildtype mice because the numbers of both partially innervated NMJs, peaking at 4 weeks after injury and comprising $43 \%$ of NMJs (Fig. 4C), and NMJs with terminal sprouting were still highly elevated at 4 weeks after injury (Fig. 4D). The number of denervated NMJs increased to $11 \%$ in the wild-type and $16 \%$ in the $\mathrm{Coll}_{3 \mathrm{al}} \mathrm{I}^{-1}$ mice at 2 weeks after injury, whereas it remained 
significantly higher in the EDL of the Coll3a1 ${ }^{-1-}$ mice at 3 weeks after injury, further indicating delayed NMJ regeneration (Fig. 4E). As in the wild-type mice, there were almost no denervated NMJs in the EDL of the Col13a1 $1^{-/-}$mice at 6 weeks after injury (Fig. 4E). Together, it can be concluded that $\mathrm{NMJ}$ regeneration in the EDL of Coll3a1 $1^{-1-}$ mice is delayed even though the NMJs in this muscle are capable of full regeneration during the follow-up time, 6 weeks (Fig. $4 A-E$ ), thus differing from those in the soleus muscle, which are not capable of doing so in Col3a1 ${ }^{-1-}$ mice (Fig. 3A-E).

\section{Muscle strength and recovery following nerve injury are impaired and incomplete in the absence of collagen XIII}

To evaluate the impact of collagen XIII deficiency on muscle strength, we performed a four-limb grid hanging test on wild-type, Col13a1 ${ }^{\mathrm{tm} / \mathrm{tm}}$, and Col13a1 ${ }^{-/-}$ mice that were positive for the Thy-1/YFP transgene before and after sciatic nerve injury. Before injury, the muscle strength of the Col13a1 $1^{-1-}$ mice was severely impaired because the mice could hold their body weight only for $\sim 60$ s compared with the maximum of $300 \mathrm{~s}$ achieved by the wild-type mice (Fig. 5A). This is in the same range as previously reported for young adult Col13a1 ${ }^{-1-}$ mice (Härönen et al., 2017) and also for aged Col13a1 ${ }^{-/-}$ mice (Table 2). At 1 week after injury, when the mice were capable of using just three limbs for hanging, the hanging times of both the wild-type and Col13a1 ${ }^{-1-}$ mice were severely shorter than in the preinjury state, validating the concept of nerve injury, and there was no difference in hanging time between the genotypes (Fig. 5A). During regeneration, the mice gradually started to use the fourth limb as it recovered, and the hanging time of the wild-type mice reached the maximum of 5 min at 3-4 weeks after injury (Fig. 5A). In contrast, the hanging time of the Col13a1 $1^{-1-}$ mice did not recover to the preinjury level during the 6 week follow-up, indicating that the injured limb had not fully recovered its muscle strength (Fig. $5 A$ ). There was no difference in hanging time and, therefore, in the recovery of muscle strength after nerve injury, in the Col13al $1^{\mathrm{tm} / \mathrm{tm}}$ mice relative to the wild-type mice, nor was there any difference in hanging time in the preinjury state (Fig. $5 A$ ). These grid hanging performance results suggest that collagen XIII is needed for proper muscle strength and for its recovery following peripheral nerve injury, and that forced expression of the transmembrane collagen XIII is sufficient for normal muscle strength and recovery.

Because loss of motor function is directly linked to denervation in the NMJs, we set out to determine motor coordination in the Thy-1/YFP-positive wild-type, Col13a $1^{\mathrm{tm} / \mathrm{tm}}$, and
Col13a1 ${ }^{-1-}$ mice, by performing gait movement analysis as assessed in terms of the SFI. There was no difference in motor coordination between the genotypes before nerve injury (Fig. $5 B$ ), and all the mice, independent of genotype, showed complete loss of locomotor coordination in the injured limb at 1 week after injury, which confirmed that the nerve crush had been successfully performed. In the wild-type mice, the locomotor performance increased to $60 \%$ at 1.5 weeks after injury, $70 \%$ at 2 weeks, $90 \%$ at 3 weeks, and reached full functionality at 4 weeks after injury, whereas the performance of the Col13a1 ${ }^{-1-}$ mice improved significantly more slowly, being $20 \%$ at 1.5 weeks after injury, $50 \%$ at 2 weeks, $49 \%$ at 3 weeks, $60 \%$ at 4 weeks, and $60 \%$ at 6 weeks after injury, and did not reach full functionality during the follow-up period, thus differing significantly from the wild-type (Fig. 5B). The locomotor performance of the Coll $3 a 1^{\mathrm{tm} / \mathrm{tm}}$ mice was initially delayed relative to the wild- 
type at 1.5 weeks after injury but reached the wild-type performance level thereafter (Fig. 5B). These results suggest that the recovery of locomotion coordination after peripheral nerve injury is severely impaired and incomplete in the absence of collagen XIII.

\section{Absence of collagen XIII results in altered soleus muscle morphology}

The results of the motor tests indicated that muscle strength is severely compromised in Col13a1 ${ }^{-/-}$mice. To further explore whether this was due to changes in muscle morphology, we performed histological analyses before sciatic nerve injury in 9- to 10 -week old wild-type and Col13a1 ${ }^{-1-}$ mice and at 6 weeks after injury (Fig. 6A). The mean fiber size in the soleus muscle before injury was significantly lower in the Col13a1 ${ }^{-/-}$mice than in the wild-type, and the number of central nuclei was significantly increased (Fig. $6 B, C$ ), suggesting soleus muscle atrophy and compensatory regeneration in the absence of collagen XIII, similar in nature to that shown in the aged mice (Fig. $1 C-E$ ). Full muscle recovery was observed at 6 weeks after injury in both the wildtype and Col13a1 ${ }^{-1-}$ mice, as their muscle histology did not differ from the preinjury condition (Fig. $6 A-C$ ). The defective $\mathrm{NMJ}$ regeneration does not contribute to the muscle pathology in the Col13a1 ${ }^{-1-}$ mice, however, as it does not progress from the preinjury state, and thus this does not seem to explain the compromised functional recovery detected in terms of muscle strength and coordination (Fig. 5A,B).

\section{Lack of collagen XIII results in altered myelination and axon diameter and number}

After failing to find a postsynaptic muscular explanation for the deficiency in functional recovery, we investigated whether there are presynaptic defects that could compromise NMJ morphology and regeneration in the absence of collagen XIII. Although nerve conduction studies on 12-week-old (Latvanlehto et al., 2010) and 52-week-old Col13a1 ${ }^{-1-}$ mice (Table 1) revealed no alterations in the function of either the motor or sensory neurons, transmission electron microscopy of preinjury sciatic nerves from the transgene-positive Col13a1 ${ }^{-/-}$mice revealed signs of polyaxonal myelination (i.e., the inclusion of numerous small axons within a single, abnormally thin myelin sheath), a manifestation of abnormal radial sorting (Fig. 6D). The sensory neurons of the Col13a1 $1^{-1-}$ mice were normal in appearance (data not shown). We never observed any signs of polyaxonal myelination in the wild-type or Col13a $1^{\mathrm{tm} / \mathrm{tm}}$ mice (data not shown). These ultrastructural analyses of sciatic nerves from Col13a1 ${ }^{-1-}$ mice therefore suggest that collagen XIII is required for regulating the normal segregation of small-caliber axons and for myelination.

A closer examination of the preinjury histology of the sciatic nerves revealed that the axons were smaller but more numerous in the Col13a1 ${ }^{-/-}$mice (Fig. 6E-G). Quantification confirmed that the Col13a1 ${ }^{-1-}$ mice had almost twice as many axons within a given area as their wild-type counterparts (Fig. $6 H$ ), that the number of small-diameter axons was significantly higher than in the wild-type (by $54 \%$ in the $<4 \mu \mathrm{m}$ size class and $43 \%$ in the $4-6$ $\mu \mathrm{m}$ class), and that the number of large-diameter axons (8-10 $\mu \mathrm{m}$ ) was significantly lower (by 51\%) (Fig. 6I). Furthermore, to determine whether myelination was been altered, the g-ratio of the axons was measured, whereupon the axons that were $<4 \mu \mathrm{m}$ or $6-8 \mu \mathrm{m}$ in diameter had significantly $(\sim 6 \%)$ thinner myelination than in the wild-type (Fig. $6 J$ ). There were no morphological differences in the axons of the Col13a $1^{\mathrm{tm} / \mathrm{tm}}$ mice, except for the increased number of those of diameter $<4 \mu \mathrm{m}$, which was $\sim 40 \%$ higher than in the wild-type (Fig. $6 I$ ). Thus, the absence/ altered expression of collagen XIII must contribute in particular to the axon diameter distribution, and to the g-ratio, of the axons. We therefore conclude that collagen XIII is required to achieve and maintain proper axon morphology and myelination.

\section{Collagen XIII deficiency leads to deposition of myelin debris and the impairment of axon regeneration after peripheral nerve injury}

The analysis of morphological changes in the sciatic nerve was next applied to the nerve repair after injury (Fig. $6 H, K-T$ ). Two parameters, the number of myelinated axons and the number of degenerated axons, were evaluated to assess axon regeneration. The number of myelinated axons decreased after nerve injury independent of the genotype, for example, at 2 weeks after injury so that the number of myelinated axons within a given area in the wild-type mice had decreased to $52 \%$ of that the preinjury value (Fig. $6 H$ ), whereas the number in the preinjury Col13a1 $1^{-1-}$ mice, which was twice as great as in the wild-type, had decreased $75 \%$, to reach a similar level (Fig. $6 H$ ). In the end, myelinated axons almost reached preinjury numbers in the wild-type and Col13a $1^{\mathrm{tm} / \mathrm{tm}}$ mice at 6 weeks after injury (Fig. $6 H$ ), whereas those in the Col13a1 ${ }^{-1-}$ mice were $30 \%$ more numerous than in the wild-type at 6 weeks after injury, although there was a tendency for incomplete recovery, in that there were 32\% less myelinated axons in the Col13a1 ${ }^{-1-}$ mice at 6 weeks after injury than in the preinjury state (Fig. $6 H$ ). This difference is not statistically significant, however. In line with this, we observed a threefold population of degenerated axons in the Col13a1 ${ }^{-/-}$mice relative to the wild-type at the preinjury stage, and the level remained significantly increased at 2 weeks after injury, fivefold at 4 weeks and approximately sixfold at 6 weeks after injury (Fig. 6T). When monitoring the recovery of the Col13a1 $1^{-1-}$ mice, the number of degenerated axons was seen to increase further to twofold at 2 weeks after injury before starting to decrease gradually to 1.6-fold at 4 weeks after injury and 1.5-fold at 6 weeks after injury relative to the preinjury values (Fig. 6T). There was just a temporary increase to approximately fourfold in the wild-type and to approximately twofold in the Col13a ${ }^{\mathrm{tm} / \mathrm{tm}}$ mice at 2 weeks after injury (Fig. 6T). Because the number of degenerated axons in the Coll3a1 ${ }^{-1-}$ mice was still elevated by fourfold relative to the wild-type at 6 weeks after injury (Fig. 6T), the results suggest that collagen XIII is required for facilitating proper axon regeneration after nerve injury.

To study whether collagen XIII is present in the adult peripheral nerves, whole-mount immunofluorescent stainings were performed. Staining of the diaphragm muscle indeed revealed positive signals not only at the NMJs, similar to what is shown in Figures $1 A$ and $2 A$, but also in association with the phrenic nerve (Fig. 7A). However, in closer examination, these structures had the appearance of blood vessels rather than neural components (Fig. $7 B$ ). This was further confirmed by double immunolabeling of the sciatic nerve where collagen XIII associated with CD-31positive blood vessels, most strongly at the branch points (Fig. $7 C, D)$.

\section{Discussion}

Morphological and physiological alterations at the NMJs result in remodeling of the motor unit (Gonzalez-Freire et al., 2014). During synapse remodeling following destabilization or injuryinduced reinnervation, axons continue to grow beyond the boundaries of the denervated motor synapses, giving rise to axonal sprouts that may or may not find another synaptic site (Rich 

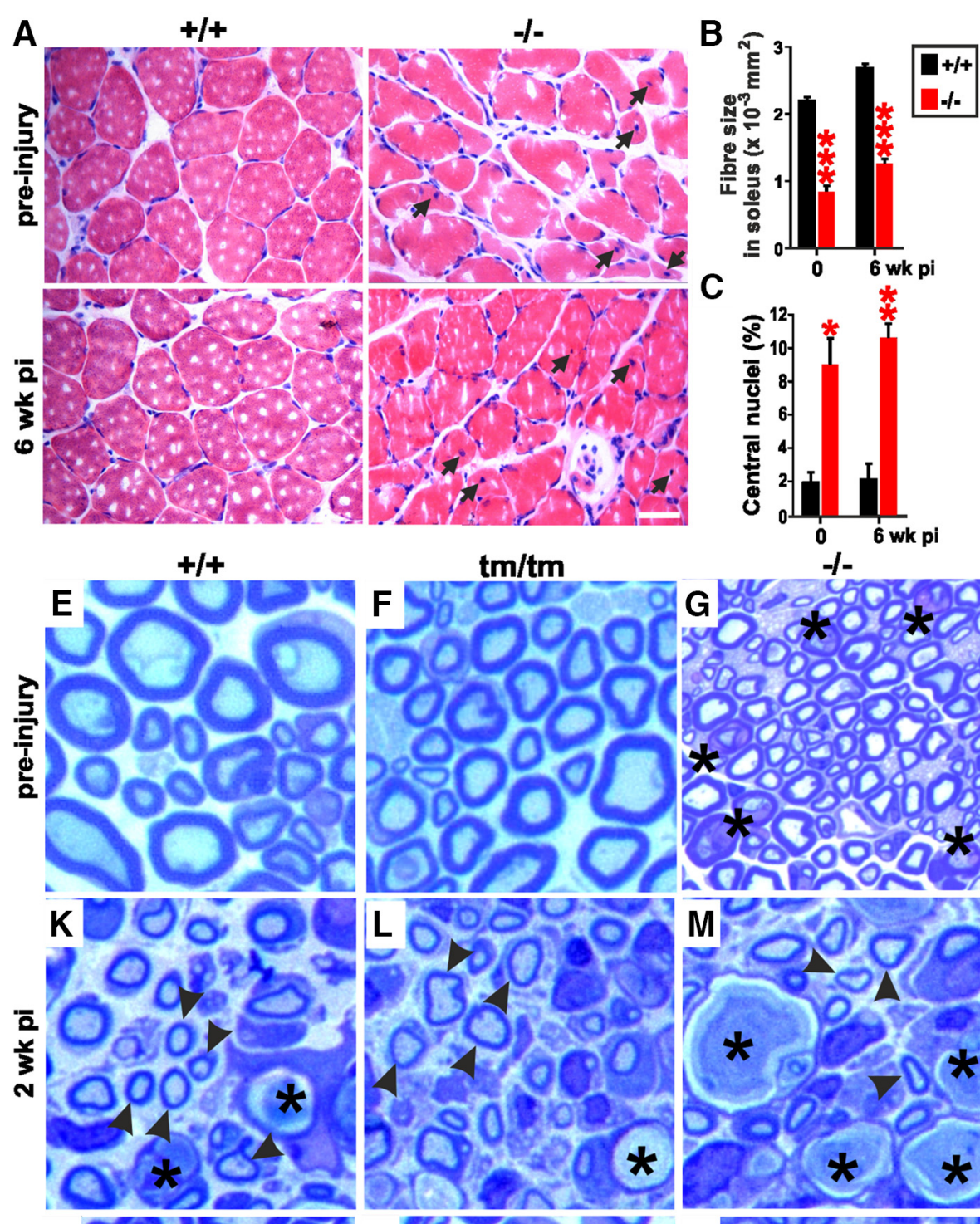

$-1$
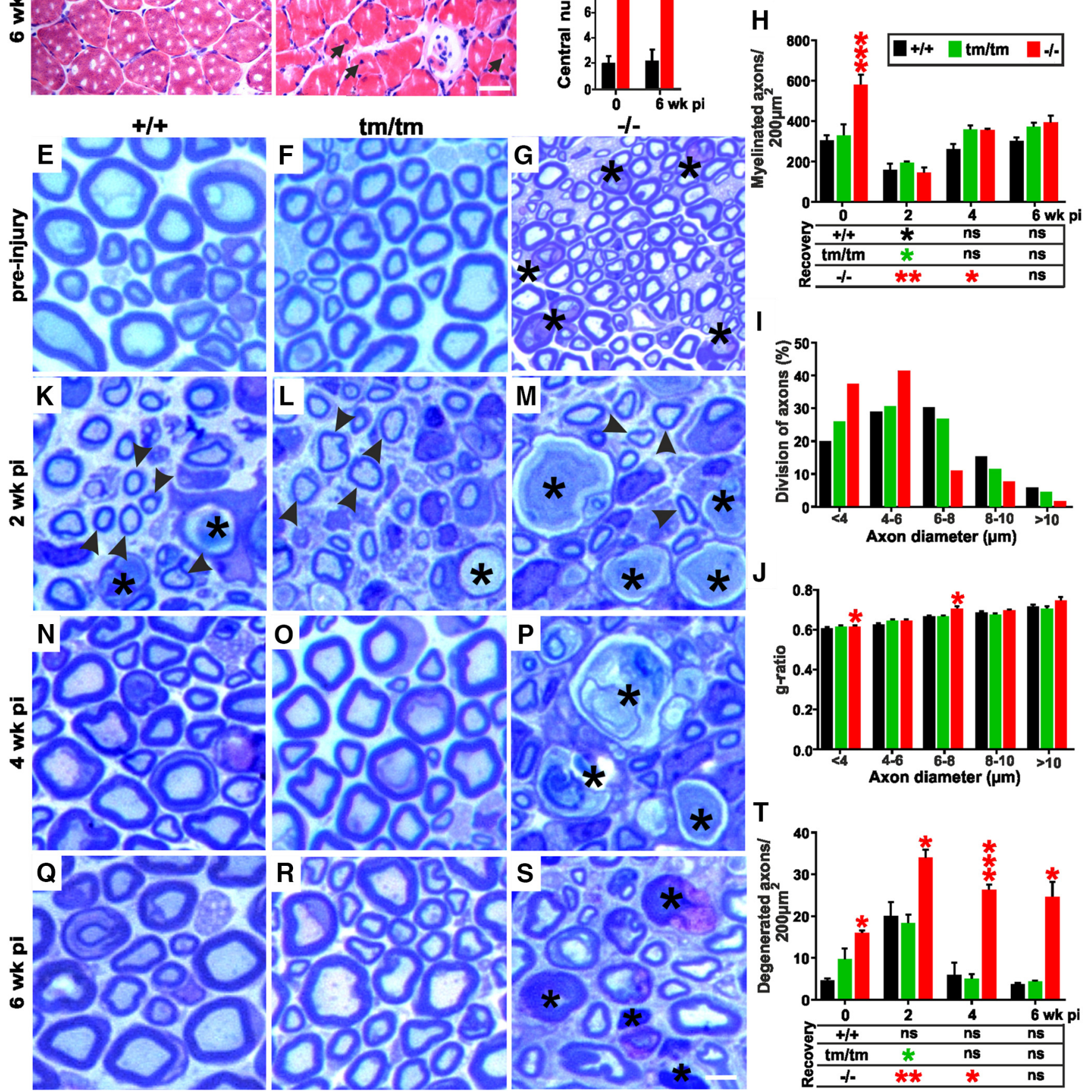

Figure 6. Muscle and axon morphology and regeneration are impaired and incomplete in Col13a1 ${ }^{-1}$ - mice. $A$, Histological evaluation of cross-sections from the soleus muscle of wild-type and Col13a1 ${ }^{-1-}$ mice stained with H\&E before injury and at 6 weeks after injury. Arrows indicate muscle fibers with central nuclei. Scale bar, $20 \mu \mathrm{m} . B, C$, Quantification of muscle fiber size before injury and 6 weeks after injury $(p<0.0001 ; p<0.0001)$ calculated fiber-wise $(\boldsymbol{B})$ and proportion of centralized nuclei $(p=0.013 ; p=0.003)(\boldsymbol{C}) . N=3$ mice/genotype; $n=100-282$ muscle fibers $(\boldsymbol{B}, \boldsymbol{C})$. D, Transmission electron microscopy of a sciatic nerve axon from a Col13a ${ }^{-1}-$ mouse before injury. Scale bar, $2 \mu \mathrm{m}$. $\boldsymbol{E}-\mathbf{G}, \boldsymbol{K}-\boldsymbol{S}$, Transversal semithin sections of sciatic nerves stained with toluidine blue from wild-type, Col13a $1^{\mathrm{tm} / \mathrm{tm}}$, and Col13a1 ${ }^{-1-}$ mice before injury $(\boldsymbol{E}-\boldsymbol{G}), 2$ weeks after injury $(\boldsymbol{K}-\boldsymbol{M}), 4$ weeks after injury $(\boldsymbol{N}-\boldsymbol{P})$, and 6 weeks (Figure legend continues.) 
A
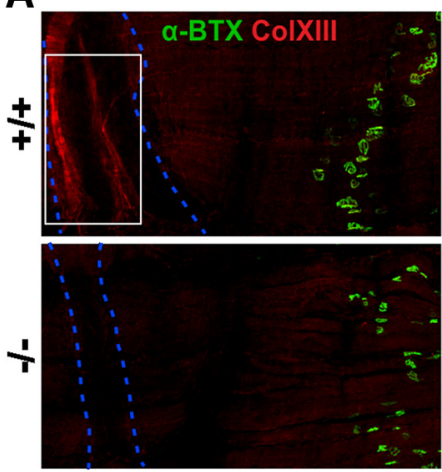

C
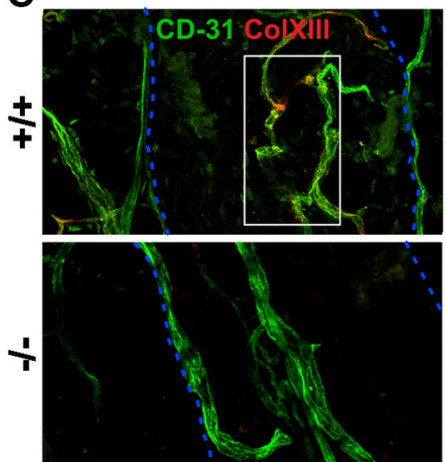
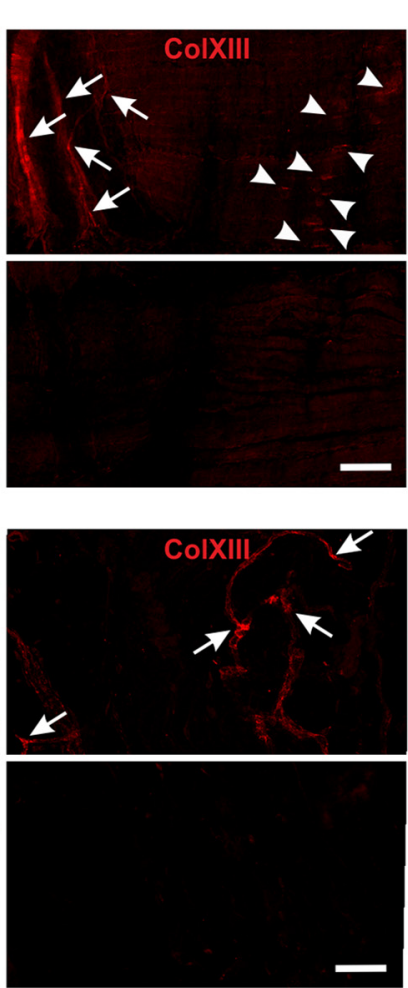

Figure 7. Collagen XIII associates with peripheral nerve vasculature. $\boldsymbol{A}-\boldsymbol{D}$, Immunofluorescent confocal images of wholemount-stained diaphragm $(\boldsymbol{A}, \boldsymbol{B})$ and sciatic nerve $(\boldsymbol{C}, \boldsymbol{D})$ of wild-type and $\mathrm{Col13a1^{-1 } -}$ mice colabeled with $\alpha$-BTX (green; $\left.\boldsymbol{A}, \boldsymbol{B}\right)$, an anti-collagen XIII/NC3 antibody (red; $\boldsymbol{A}-\boldsymbol{D})$, an anti-neurofilament antibody (NF; blue; $\boldsymbol{A}-\boldsymbol{D}$ ) to show nerves and an anti-CD-31 (green; $\boldsymbol{C}, \boldsymbol{D})$ to show blood vessels. Blue hyphenated lines indicate phrenic $(\boldsymbol{A})$ and sciatic nerve ( $\boldsymbol{C}$. Arrows indicate collagen XIII accumulation in blood vessels and arrowheads at NMJs. $\boldsymbol{A}, \boldsymbol{C}$, Inset, magnified in $\boldsymbol{B}$ and $\boldsymbol{D}$, respectively. Scale bars: $\boldsymbol{A}, \boldsymbol{B}, 50 \mu \mathrm{m} ; \boldsymbol{C}$, D, $100 \mu \mathrm{m}$

and Lichtman, 1989; Kang and Lichtman, 2013; Darabid et al., 2014). This description mirrors our findings, where the structural integrity of the NMJs is impaired and they undergo reinnervation, as demonstrated by the presence of terminal sprouting, partial innervation, and abundance of denervated NMJs in the collagen XIII knock-out mice. These features show that NMJs are unstable and incapable of fully maturing when collagen XIII is absent. Moreover, destabilization of motor syn-

(Figure legend continued.) after injury (Q-S). Arrowheads indicate myelinated axons. Asterisks indicate degenerated axons. Scale bar, $10 \mu \mathrm{m}$. $\boldsymbol{H}$, Quantification of the mean number of myelinated axons in a $200 \mu \mathrm{m}^{2}$ area. Significance in Col13a1 ${ }^{-1-}$ mice relative to the wildtype before injury $(p<0.0001)$. Significance within the wild-type and Col13a1 ${ }^{-1-}$ mice from before injury to 2 weeks after injury ( $p=0.023$ and $p=0.002$, respectively). $I$, Numbers of axons according to their diameter. $J$, $g$-ratios of axons of specific diameters in Col13a $1^{-1-}$ mice relative to the wild-type before injury $(<4 \mu \mathrm{m} ; p=0.019 ; 6-8 \mu \mathrm{m} ; p=0.016) ; n=$ 231 axons/genotype $(I, J) . T$, Quantification of degenerated axons in a $200 \mu \mathrm{m}^{2}$ area in Col13a ${ }^{-1-}$ mice relative to the wild-type before injury and at 2,4 , and 6 weeks after injury $(p=0.015, p=0.026, p=0.001$, and $p=0.023$, respectively). Significance of the difference in the number of degenerated axons in the $\mathrm{Co} / 13 \mathrm{a} 1^{\mathrm{tm} / \mathrm{tm}}$ mice between the preinjury to 2 weeks after injury values $(p=0.050)$ and in Col13a1 ${ }^{-1-}$ mice between the preinjury to 2 and 4 weeks after injury values $(p=0.002, p=0.046)$. Significances of differences between the wild-type and $\mathrm{Col} / 3 \mathrm{a} 1^{\mathrm{tm} / \mathrm{tm}}$ mice and between the wild-type and Col13a1 ${ }^{-1-}$ mice at specified time points, calculated by the unpaired $t$ test or the Mann-Whitney test, are shown with green and red asterisks above the columns, respectively. Significances of differences over time within the wild-type, $\mathrm{Co} / 13 \mathrm{a} 1^{\mathrm{tm} / \mathrm{tm}}$, and $\mathrm{Col} 13 \mathrm{a} 1^{-1-}$ mice, calculated by ANOVA followed by the Bonferroni post hoc test or the Kruskal-Wallis test with correction for multiple comparisons using the Benjamin-Hochberg procedure, are shown in tables below graphs. $N=3$ or 4 mice/ genotype/time point. ${ }^{*} p \leq 0.05,{ }^{* *} p \leq 0.01,{ }^{* * *} p \leq 0.001$.
B
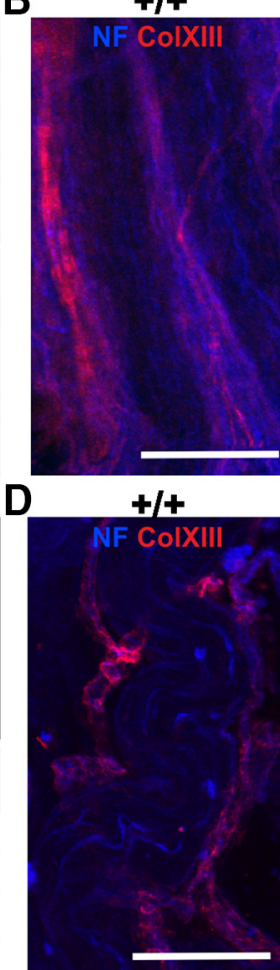

apses results in a decline in the diameter of the motor axons, as found here in the Col13a1 ${ }^{-1-}$ mice, which results in a deterioration in communication between the nervous and muscular systems, causing a decay in skeletal muscle strength and muscle mass (Gonzalez-Freire et al., 2014). The axons of the sciatic nerves are swollen in appearance in Col13a1 ${ }^{-/-}$ mice (Härönen et al., 2017), a characteristic hallmark of neurodegeneration (Coleman et al., 2005; Smith and Jeffery, 2006), indicating that collagen XIII plays a role in motor axon survival and its deficiency may thus predispose axons to regeneration. Consistent with this finding, we have previously observed Schwann cells invading into the synaptic cleft in the absence of collagen XIII (Latvanlehto et al., 2010), a phenomenon seen at mammalian NMJs in pathological conditions, such as nerve terminal degeneration (Miledi and Slater, 1970; Winlow and Usherwood, 1975). Slow-twitch motor units appear to be especially vulnerable to distal motor neuron axonopathies (Murray et al., 2010). As shown here, NMJs, especially in the slow-twitch soleus muscle, undergo heavy remodeling in the absence of collagen XIII, and earlier studies have shown this to result in a biased muscle fiber-type distribution, slight muscle fiber regeneration, and atrophy following NMJ maturation (Härönen et al., 2017). It should be noted that lower limb muscles are essential for performing functional activities by which the aged population can maintain their independence and quality of life (Christensen et al., 2006). In line with this, permanently altered muscle function in the collagen XIII-deficient mice resulted in altered gait, specifically affecting the hind limbs. Most significantly, axonal atrophy and degenerative changes were only seen in the myelinated axons. Thus, as collagen XIII is located at the NMJs, it appears that the effect of its deficiency is restricted to the motor neurons. This is consistent with our behavioral observation that the Col13a1 ${ }^{-1-}$ mice exhibited primarily motor impairments.

Compromised structural integrity and functional capacity in collagen XIII-deficient mice, combined with motor nerve axonopathy and continuous motor synapse remodeling, thus gradually lead to sustained changes in muscle architecture and operation. This leads specifically to compromised function of the hind limbs, however, but not the front limbs, pointing to permanent alterations in the peripheral motor unit. CMSs can be progressive, like those caused by mutations in DOK7, MuSK, and COLQ (Rodríguez Cruz et al., 2014). Surprisingly, we did not detect any further deterioration of either the muscle morphology or strength in the aged Col13a1 $1^{-/-}$mice, at least not until $\sim 1$ year 9 months of age. As shown here, NMJ morphology is significantly impaired in aged Coll3a1 ${ }^{-1-}$ mice relative to agedmatched wild-type mice but does not decay any further after early adulthood, suggesting that the absence of collagen XIII does not significantly affect NMJ morphology upon aging and supporting its relevance in achieving dynamic stability in NMJ maturation. 
Therefore, mice aged $\sim \geq 2$ years should be used when studying the mechanisms in the motor synapse pathology involved in the later stages of CMS19 disease. In addition to symptoms characteristic of myasthenia, collagen XIII-deficient mice showed signs of reduced anxiety and fear of open spaces, as well as shivering, which worsened with age. An earlier study suggested of a link between COL13A1 and hereditary Parkinson's disease (Davis et al., 2013), but together these results of the emotional behavior and motor tests (e.g., shortening of the stride length of hind limbs, but not the forepaws) strongly support neuromuscular impairment, specifically (Taylor et al., 2010). Although neuromuscular impairments do not progress at least before 1 year 9 months of age, collagen XIII-deficient mice from $\sim 1$ year 4 months of age onwards occasionally show rapid deterioration in general health (data not shown), suggesting the possibility of pathological progression in other tissues system(s) in addition to the neuromuscular system at advanced ages.

Peripheral nerve crush experiments were conducted to elucidate whether the altered NMJ morphology and function in the Col13a1 ${ }^{-1-}$ mice affected the reinnervation process, NMJ regeneration, and functional recovery. The collagen XIII-deficient mice indeed showed incomplete NMJ regeneration and functional recovery even at 6 weeks after injury, whereas the wild-type and Coll $3 a 1^{\mathrm{tm} / \mathrm{tm}}$ mice had achieved full NMJ reinnervation and complete functional recovery by 4 weeks after injury. The next important question was whether impaired postinjury NMJ regeneration, muscle strength, and functional recovery were mainly attributable to presynaptic or postsynaptic defects. The fact that the muscle morphology of the Col13a1 ${ }^{-1-}$ mice at 6 weeks after injury resembled the preinjury architecture suggests that NMJ regeneration defects are not mainly attributable or the results of major postsynaptic defects. It is clear, however, that collagen XIII is indeed needed for the maintenance of muscle morphology and strength both before and after peripheral nerve injury. This directed our attention to investigating possible presynaptic reasons for the poor and incomplete NMJ regeneration and functional recovery seen in Coll3a1 ${ }^{-/-}$mice. The presence of polyaxonal myelination in the Col13a1 ${ }^{-1-}$ nerves suggests that the absence of collagen XIII causes an abnormality in radial sorting by which immature Schwann cells segregate the axons and establish a correct 1:1 axon-Schwann cell relationship with large-caliber axons before the formation of myelin sheaths (Saito et al., 2003; Rasi et al., 2010; Chang et al., 2016). It has been reported that polyaxonal myelination may appear in young wildtype mice during active myelination but is corrected by further development (Rasi et al., 2010). As we studied only adult mice, we did not observe any sign of polyaxonal myelination in the adult wild-type mice. Polyaxonal myelination in Col13a1 ${ }^{-1-}$ mice is suggestive of a continuous remodeling process and/or a diminished and/or delayed ability to establish the correct axonSchwann cell ratio, possibly due to compromised stabilization of the NMJs, which may delay postinjury motor synapse recovery. Moreover, the peripheral nerves of the Col13a1 ${ }^{-1-}$ mice included reduced myelin sheath thicknesses in the axons. This may reflect delayed motor nerve maturation due to NMJ instability. Furthermore, the decrease in axon diameter detected in the collagen XIII-deficient mice may arise from alterations in motor unit size and the multiplicity of axonal branching because complex terminal branching has been found earlier to be compromised in collagen XIII knock-out mice (Härönen et al., 2017). Moreover, increased axon regeneration could also in part explain these changes seen in axons of collagen XIII knock-out mice. Together, absence of collagen XIII has effects on both axonal segregation and myelination that are most probably mediated in a retrograde manner via compromised NMJ integrity rather than being direct effects on collagen XIII expression in the motor nerves or Schwann cells. In this study, we did not find collagen XIII immunosignals reported earlier in developing nerve structures and adult nerve fascia (Hägg et al., 2001; Sund et al., 2001). This discrepancy may, however, result from use of other antibodies than in the present study (which were confirmed in terms of specificity by staining of knock-out mouse samples). In our opinion, the possibility of cross-reaction between the highly homologous transmembrane collagens, XIII, XXIII, and/or XXV, cannot fully be excluded in earlier studies.

We found a delay in myelin debris removal in Col13a1 ${ }^{-1-}$ mice even at 6 weeks after injury, and consequently a delay in axon regeneration, even though complete axon and myelin debris removal and axon regeneration were achieved at 4 weeks after injury in the wild-type and Col13a $1^{\mathrm{tm} / \mathrm{tm}}$ mice. These observations suggest that impaired axon regeneration in Coll3a1 ${ }^{-1-}$ mice is at least partly attributable to delayed axon and myelin removal, one possible reason for which may be impaired macrophage recruitment to the distal injury site. Activation of macrophages is a self-defense response that helps the injured nerve clear away myelin debris and promote axonal regeneration (Zhang et al., 2013). Collagen XIII has been found to be associated with blood vessels (Heikkinen et al., 2012) and has been shown to promote $\alpha 1 \beta 1$-integrin-positive monocyte recruitment in a kidney fibrosis model (Dennis et al., 2010). Interestingly, here collagen XIII was found to associate with blood vessels supplying peripheral nerves. We pursued defining macrophage numbers in crushed sciatic nerves at the final time point, at 6 weeks after injury, and observed strong signals in both genotypes. However, a high variation between individual samples (79.3 \pm 25.6/0.1 $\mathrm{mm}^{2}$ for wild-type and $88.6 \pm 16.8$ for Col13a1 ${ }^{-1-}$ mice, $p=$ $0.772, N=4)$ made it impossible to identify possible subtle difference between the genotypes. Further studies, especially at earlier time points more relevant in macrophage recruitment, would be beneficial to ascertain whether macrophage activity is collagen XIII-related, which would cause delayed debris removal in Col13a1 $1^{-1-}$ mice and thereby axon regeneration. We have shown in a recent study that primarily sarcolemmal-anchored collagen XIII contributes to transsynaptic adhesion, thereby enhancing synaptic organization, complexity, and function (Härönen et al., 2017). This may explain why we did not observe any impairment or delay in NMJ regeneration and functional recovery in our Col13a $1^{\mathrm{tm} / \mathrm{tm}}$ mice. All in all, NMJ regeneration defects, including incomplete functional recovery, are mainly attributable to presynaptic defects partially preexisting in collagen XIII-deficient mice before injury. The present results imply that facilitating clearance of axon debris might be a potential approach for treating peripheral nerve injury and achieving normal functional recovery in cases of collagen XIII deficiency, including CMS19 patients.

In conclusion, the developmental defects found in NMJ maturation are evidently not markedly progressive, at least not up to 1 year 9 months of age in mice, and a critical role can be demonstrated for collagen XIII in an in vivo mouse model of sciatic nerve injury and NMJ and axon regeneration. The absence of collagen XIII results in impaired and incomplete NMJ and axon regeneration and incomplete functional recovery after peripheral nerve injury. Taken collectively, these data support the concept of therapeutic intervention with collagen XIII activators following peripheral nerve injury. 


\section{References}

Bain JR, Mackinnon SE, Hunter DA (1989) Functional evaluation of complete sciatic, peroneal, and posterior tibial nerve lesions in the rat. Plast Reconstr Surg 83:129-138. CrossRef Medline

Balice-Gordon RJ, Lichtman JW (1993) In vivo observations of pre- and postsynaptic changes during the transition from multiple to single innervation at developing neuromuscular junctions. J Neurosci 13:834-855. CrossRef Medline

Barik A, Li L, Sathyamurthy A, Xiong WC, Mei L (2016) Schwann cells in neuromuscular junction formation and maintenance. J Neurosci 36: 9770-9781. CrossRef Medline

Blake DJ, Weir A, Newey SE, Davies KE (2002) Function and genetics of dystrophin and dystrophin-related proteins in muscle. Physiol Rev 82: 291-329. CrossRef Medline

Chang KJ, Redmond SA, Chan JR (2016) Remodeling myelination: implications for mechanisms of neural plasticity. Nat Neurosci 19:190-197. CrossRef Medline

Christensen U, Støvring N, Schultz-Larsen K, Schroll M, Avlund K (2006) Functional ability at age 75: is there an impact of physical inactivity from middle age to early old age? Scand J Med Sci Sports 16:245-251. CrossRef Medline

Coleman MP, Adalbert R, Beirowski B (2005) Neuroprotective strategies in MS: lessons from C57BL/wld(S) mice. J Neurol Sci 233:133-138. CrossRef Medline

Darabid H, Perez-Gonzalez AP, Robitaille R (2014) Neuromuscular synaptogenesis: coordinating partners with multiple functions. Nat Rev Neurosci 15:703-718. CrossRef Medline

Davis MF, Cummings AC, D’Aoust LN, Jiang L, Velez Edwards DR, Laux R, Reinhart-Mercer L, Fuzzell D, Scott WK, Pericak-Vance MA, Lee SL, Haines JL (2013) Parkinson disease loci in the mid-Western Amish. Hum Genet 132:1213-1221. CrossRef Medline

de Medinaceli L, Freed WJ, Wyatt RJ (1982) An index of the functional condition of rat sciatic nerve based on measurements made from walking tracks. Exp Neurol 77:634-643. CrossRef Medline

Dennis J, Meehan DT, Delimont D, Zallocchi M, Perry GA, O’Brien S, Tu H, Pihlajaniemi T, Cosgrove D (2010) Collagen XIII induced in vascular endothelium mediates alphalbetal integrin-dependent transmigration of monocytes in renal fibrosis. Am J Pathol 177:2527-2540. CrossRef Medline

Fawcett JW, Keynes RJ (1990) Peripheral nerve regeneration. Annu Rev Neurosci 13:43-60. CrossRef Medline

Feng G, Mellor RH, Bernstein M, Keller-Peck C, Nguyen QT, Wallace M, Nerbonne JM, Lichtman JW, Sanes JR (2000) Imaging neuronal subsets in transgenic mice expressing multiple spectral variants of GFP. Neuron 28:41-51. CrossRef Medline

Gonzalez-Freire M, de Cabo R, Studenski SA, Ferrucci L (2014) The neuromuscular junction: aging at the crossroad between nerves and muscle. Front Aging Neurosci 6:208. CrossRef Medline

Griffin MF, Malahias M, Hindocha S, Khan WS (2014) Peripheral nerve injury: principles for repair and regeneration. Open Orthop J 8:199-203. CrossRef Medline

Hägg P, Rehn M, Huhtala $P$, Väisänen T, Tamminen M, Pihlajaniemi T (1998) Type XIII collagen is identified as a plasma membrane protein. J Biol Chem 273:15590-15597. CrossRef Medline

Hägg P, Väisänen T, Tuomisto A, Rehn M, Tu H, Huhtala P, Eskelinen S, Pihlajaniemi T (2001) Type XIII collagen: a novel cell adhesion component present in a range of cell-matrix adhesions and in the intercalated discs between cardiac muscle cells. Matrix Biol 19:727-742. CrossRef Medline

Härönen H, Zainul Z, Tu H, Naumenko N, Sormunen R, Miinalainen I, Shakirzyanova A, Oikarainen T, Abdullin A, Martin P, Santoleri S, Koistinaho J, Silman I, Giniatullin R, Fox MA, Heikkinen A, Pihlajaniemi T (2017) Collagen XIII secures pre- and postsynaptic integrity of the neuromuscular synapse. Hum Mol Genet 26:2076-2090. CrossRef Medline

Heikkinen A, Tu H, Pihlajaniemi T (2012) Collagen XIII: a type II transmembrane protein with relevance to musculoskeletal tissues, microvessels and inflammation. Int J Biochem Cell Biol 44:714-717. CrossRef Medline

Hettwer S, Lin S, Kucsera S, Haubitz M, Oliveri F, Fariello RG, Rüegg MA, Vrijbloed JW (2014) Injection of a soluble fragment of neural agrin (NT-1654) considerably improves the muscle pathology caused by the disassembly of the neuromuscular junction. PLoS One 9:e88739. CrossRef Medline

Inserra MM, Bloch DA, Terris DJ (1998) Functional indices for sciatic, peroneal, and posterior tibial nerve lesions in the mouse. Microsurgery 18: 119-124. CrossRef Medline

Kang H, Lichtman JW (2013) Motor axon regeneration and muscle reinnervation in young adult and aged animals. J Neurosci 33:19480-19491. CrossRef Medline

Kang H, Tian L, Thompson W (2003) Terminal Schwann cells guide the reinnervation of muscle after nerve injury. J Neurocytol 32:975-985. CrossRef Medline

Kang H, Tian L, Mikesh M, Lichtman JW, Thompson WJ (2014) Terminal Schwann cells participate in neuromuscular synapse remodeling during reinnervation following nerve injury. J Neurosci 34:6323-6333. CrossRef Medline

Koivisto H, Leinonen H, Puurula M, Hafez HS, Barrera GA, Stridh MH, Waagepetersen HS, Tiainen M, Soininen P, Zilberter Y, Tanila H (2016) Chronic pyruvate supplementation increases exploratory activity and brain energy reserves in young and middle-aged mice. Front Aging Neurosci 8:41. CrossRef Medline

Kvist AP, Latvanlehto A, Sund M, Eklund L, Väisänen T, Hägg P, Sormunen R, Komulainen J, Fässler R, Pihlajaniemi T (2001) Lack of cytosolic and transmembrane domains of type XIII collagen results in progressive myopathy. Am J Pathol 159:1581-1592. CrossRef Medline

Latvanlehto A, Fox MA, Sormunen R, Tu H, Oikarainen T, Koski A, Naumenko N, Shakirzyanova A, Kallio M, Ilves M, Giniatullin R, Sanes JR, Pihlajaniemi T (2010) Muscle-derived collagen XIII regulates maturation of the skeletal neuromuscular junction. J Neurosci 30:12230-12241. CrossRef Medline

Li Y, Lee Y, Thompson WJ (2011) Changes in aging mouse neuromuscular junctions are explained by degeneration and regeneration of muscle fiber segments at the synapse. J Neurosci 31:14910-14919. CrossRef Medline

Logan CV, Cossins J, Rodríguez Cruz PM, Parry DA, Maxwell S, MartínezMartínez P, Riepsaame J, Abdelhamed ZA, Lake AV, Moran M, Robb S, Chow G, Sewry C, Hopkins PM, Sheridan E, Jayawant S, Palace J, Johnson CA, Beeson D (2015) Congenital myasthenic syndrome type 19 is caused by mutations in COL13A1, encoding the atypical non-fibrillar collagen type XIII alphal chain. Am J Hum Genet 97:878-885. CrossRef Medline

Marques MJ, Conchello JA, Lichtman JW (2000) From plaque to pretzel: fold formation and acetylcholine receptor loss at the developing neuromuscular junction. J Neurosci 20:3663-3675. Medline

Miledi R, Slater CR (1970) On the degeneration of rat neuromuscular junctions after nerve section. J Physiol 207:507-528. CrossRef Medline

Murray LM, Talbot K, Gillingwater TH (2010) Review: neuromuscular synaptic vulnerability in motor neurone disease: amyotrophic lateral sclerosis and spinal muscular atrophy. Neuropathol Appl Neurobiol 36:133156. CrossRef Medline

Punga AR, Rüegg MA (2012) Signaling and aging at the neuromuscular synapse: lessons learnt from neuromuscular diseases. Curr Opin Pharmacol 12:340-346. CrossRef Medline

Rasi K, Hurskainen M, Kallio M, Stavén S, Sormunen R, Heape AM, Avila RL, Kirschner D, Muona A, Tolonen U, Tanila H, Huhtala P, Soininen R, Pihlajaniemi T (2010) Lack of collagen XV impairs peripheral nerve maturation and, when combined with laminin-411 deficiency, leads to basement membrane abnormalities and sensorimotor dysfunction. J Neurosci 30:14490-14501. CrossRef Medline

Rich MM, Lichtman JW (1989) In vivo visualization of pre- and postsynaptic changes during synapse elimination in reinnervated mouse muscle. J Neurosci 9:1781-1805. CrossRef Medline

Rodríguez Cruz PM, Palace J, Beeson D (2014) Inherited disorders of the neuromuscular junction: an update. J Neurol 261:2234-2243. CrossRef Medline

Saito F, Moore SA, Barresi R, Henry MD, Messing A, Ross-Barta SE, Cohn RD, Williamson RA, Sluka KA, Sherman DL, Brophy PJ, Schmelzer JD, Low PA, Wrabetz L, Feltri ML, Campbell KP (2003) Unique role of dystroglycan in peripheral nerve myelination, nodal structure, and sodium channel stabilization. Neuron 38:747-758. CrossRef Medline

Schaefer AM, Sanes JR, Lichtman JW (2005) A compensatory subpopulation of motor neurons in a mouse model of amyotrophic lateral sclerosis. J Comp Neurol 490:209-219. CrossRef Medline

Serra A, Ruff RL, Leigh RJ (2012) Neuromuscular transmission failure in 
myasthenia gravis: decrement of safety factor and susceptibility of extraocular muscles. Ann N Y Acad Sci 1275:129-135. CrossRef Medline

Smith PM, Jeffery ND (2006) Histological and ultrastructural analysis of white matter damage after naturally-occurring spinal cord injury. Brain Pathol 16:99-109. CrossRef Medline

Souza PV, Batistella GN, Lino VC, Pinto WB, Annes M, Oliveira AS (2016) Clinical and genetic basis of congenital myasthenic syndromes. Arq Neuropsiquiatr 74:750-760. CrossRef Medline

Sulaiman W, Gordon T (2013) Neurobiology of peripheral nerve injury, regeneration, and functional recovery: from bench top research to bedside application. Ochsner J 13:100-108. Medline

Sund M, Väisänen T, Kaukinen S, Ilves M, Tu H, Autio-Harmainen H, Rauvala H, Pihlajaniemi T (2001) Distinct expression of type XIII collagen in neuronal structures and other tissues during mouse development. Matrix Biol 20:215-231. CrossRef Medline

Taylor TN, Greene JG, Miller GW (2010) Behavioral phenotyping of mouse models of Parkinson's disease. Behav Brain Res 211:1-10. CrossRef Medline
Tu H, Huhtala P, Lee HM, Adams JC, Pihlajaniemi T (2015) Membraneassociated collagens with interrupted triple-helices (MACITs): evolution from a bilaterian common ancestor and functional conservation in $C$. elegans. BMC Evol Biol 15:281. CrossRef Medline

Väisänen MR, Väisänen T, Pihlajaniemi T (2004) The shed ectodomain of type XIII collagen affects cell behaviour in a matrix-dependent manner. Biochem J 380:685-693. CrossRef Medline

Valdez G, Tapia JC, Kang H, Clemenson GD Jr, Gage FH, Lichtman JW, Sanes JR (2010) Attenuation of age-related changes in mouse neuromuscular synapses by caloric restriction and exercise. Proc Natl Acad Sci U S A 107:14863-14868. CrossRef Medline

Winlow W, Usherwood PN (1975) Ultrastructural studies of normal and degenerating mouse neuromuscular junctions. J Neurocytol 4:377-394. CrossRef Medline

Zhang L, Johnson D, Johnson JA (2013) Deletion of Nrf2 impairs functional recovery, reduces clearance of myelin debris and decreases axonal remyelination after peripheral nerve injury. Neurobiol Dis 54:329-338. CrossRef Medline 